\title{
City Flood Disaster Scenario Simulation based on 1D-2D Coupled Rain-flood Model: A Case Study in Luoyang, China
}

Chengshuai Liu

Zhengzhou University

Fan Yang

Zhengzhou University

Caihong Hu ( $\nabla$ hucaihong@zzu.edu.cn )

Zhengzhou University

Yichen Yao

Zhengzhou University

Yue Sun

Zhengzhou University

Bin Zha

Luoyang Water Resources Surveying \& Designing Co., Ltd

\section{Research Article}

Keywords: 1D-2D coupled model, Complex underlying surface, City flood, Inundation, Urban hydrology

Posted Date: May 5th, 2021

DOI: https://doi.org/10.21203/rs.3.rs-469710/v1

License: (c) (i) This work is licensed under a Creative Commons Attribution 4.0 International License.

Read Full License 


\section{City flood disaster scenario simulation based on 1D-2D coupled rain-flood}

model: A case study in Luoyang, China

Chengshuai $\mathrm{Liu}^{1}$, Fan Yang ${ }^{1,2}$, Caihong $\mathrm{Hu}^{1,}$, ${ }^{\square}$ Yichen $\mathrm{Yao}^{1}$, Yue Sun ${ }^{1}$, Bin Zha ${ }^{2}$

1 School of Water Conservancy Science and Engineering Zhengzhou University, Zhengzhou, 450001, China

2 Luoyang Water Resources Surveying \& Designing Co., Ltd, Luoyang, 471000, China

${ }^{\square}$ Corresponding Author: Caihong $\mathrm{Hu}$, School of Water Conservancy and Engineering, Zhengzhou University, 450001, China

Email address: hucaihong@zzu.edu.cn

\section{Abstract}

In order to realize the reproduction and simulation of urban rainstorm and waterlogging scenarios with complex underlying surfaces. Based on the Mike series models, we constructed an urban storm-flood coupling model considering onedimensional river channels, two-dimensional ground and underground pipe networks. Luoyang City was used as a pilot to realize the construction of a one-dimensional and two-dimensional coupled urban flood model and flood simulation. where is located in the western part of Henan Province, China. The coupled model was calibrated and verified by the submerged water depths of 16 survey points in two historical storms flood events. The average relative error of the calibration simulated water depth was $22.65 \%$, and the average absolute error was $13.93 \mathrm{~cm}$; the average relative error of the verified simulated water depth was $15.27 \%$, The average absolute error is $7.54 \mathrm{~cm}$, and 
the simulation result is good. Finally, 28 rains with different return periods and different durations were designed to simulate and analyze the rainstorm inundation in the downtown area of Luoyang. The result shows that the $R^{2}$ of rainfall and urban rainstorm inundation is 0.8776 , and the $R^{2}$ of rainfall duration and urban rainstorm inundation is 0.8141. Therefore, rainfall is the decisive factor in the formation of urban waterlogging disasters, which is actually the rainfall duration. The study results have important practical significance for urban flood prevention, disaster reduction and traffic emergency management.

Keywords: 1D-2D coupled model, Complex underlying surface, City flood, Inundation, Urban hydrology

\section{Introduction}

With the acceleration of urbanization, population density and economic output increase, urban flood disasters have gradually become a research hotspot ${ }^{1}$. As the process of urbanization continues to accelerate, the natural and ecological systems in the main urban area and surrounding areas have changed ${ }^{2}$. The changes in urban hydrological processes have gradually increased the threat of urban rainstorm disasters ${ }^{3}$. As an important method for evaluating and preventing urban rainstorm disasters ${ }^{4}$, numerical models can provide important technical support for flood control and drainage ${ }^{5}$.

The city is a region, not a closed watershed ${ }^{1}$. It has both the problem of overflowing rivers and waterlogging caused by heavy rains ${ }^{6}$. The simulation forecast of heavy rain and waterlogging in cities with complex underlying surfaces is much more 
difficult than that of natural basin flood forecasts ${ }^{7}$. The complexity of the underlying surface of the city is mainly reflected in the hard ground and the underground drainage pipe network, but often only consider the hydrodynamic simulation calculation of the urban pipe network, it is difficult to describe the real urban rainstorm and waterlogging process, which leads to urban rain flood. The simulation forecast accuracy of the model is also difficult to guarantee ${ }^{8}$.

Urban storm flood model is essentially a type of hydrological model or hydrodynamic model, and its basic development process is basically the same as that of traditional hydrological or hydrodynamic $\operatorname{model}^{9}$. In 1986, the first generation of MIKE model was launched ${ }^{10}$, which integrated many new algorithms and data preprocessing and other new technologies in the algorithm innovation stage into the same simulation platform, which promoted the development of urban flood simulation technology and made urban flood modeling more convenient and efficient ${ }^{11}$. In the meantime, many representative urban rain and flood models have also been produced. In 1998, the Wallingford model was improved and introduced the Inforworks CS model ${ }^{12}$, the European natural disaster engineering flood project team developed the LISFLOOD model in $2010^{13}$, and the Disaster Mitigation Center of the Ministry of Water Resources of the Chinese Academy of Water Sciences launched IFMS/URBAN model ${ }^{14}$. These model methods are also widely used in the simulation and risk assessment of urban floods. Guoru Huang ${ }^{15}$ took the Donghaoyong River Basin in Guangzhou City as the research area and comprehensively considered the characteristics of urban rainfall, runoff, topography and drainage system, and 
constructed a one-dimensional-two-dimensional coupled urban flood simulation model based on InfoWorks ICM. Zischg et al. ${ }^{16}$ simulated flood risks in 4 regions of Switzerland based on a two-dimensional hydrodnamic model and verified their assessment results with insurance claims data. Roland et al. ${ }^{17}$ conducted a flood risk assessment based on the MIKE FLOOD model coupled with MIKE URBAN and MIKE 21 in a certain area of Melbourne, Australia under different urban development levels and climate change scenarios. These studies have also achieved good study results.

In the previous application of urban storm and flood numerical simulation, underground drainage pipe flow was simulated by one-dimensional Saint-Venant equations, and surface water flow was simulated by two-dimensional shallow water equations ${ }^{18}$. The model also considers the flow exchange between the surface and the underground drainage system, and establishes a connection between the two at rainwater outlets or inspection wells. Predecessors have done a lot of research on simulating surface water flow and underground drainage pipe flow in one- and twodimensional coupled models ${ }^{19-20}$. The SWMM 1 D model was added to the TUFLOW 2D model to form XP-SWMM ${ }^{21}$. InfoWorks ICM integrates InfoWorks CS and InfoWorks RS for one- and two-dimensional coupled modeling ${ }^{22}$. However, these models are incomplete in describing the urban flood process, because the urban inland rivers are not included in the urban storm flood simulation calculation.

This paper first introduces a newly established model, which is based on MIKE 11, MIKE 21 and MIKE Urban coupled underground drainage systems, river networks, and surface flows (Fig.1). This 2D model is efficient for shallow-water flows and uses 
the lower-upper symmetric Gauss-Seidel (LU-SGS) implicit dual time-stepping method based on structured grids. Then, we explore the urban inundation response to rainstorm duration in a case study of the Luoyang City Center. Finally, based on the MIKE FLOOD system model, taking into account multiple elements such as urban pipe network, topography, drainage canals, rivers, buildings, etc., construct a storm and flood coupling model under the complex underlying surface conditions of the city, and realize the coupling of ground overflow-pipe network confluence-river confluence Flood inundation simulation and heavy rain scenario application.

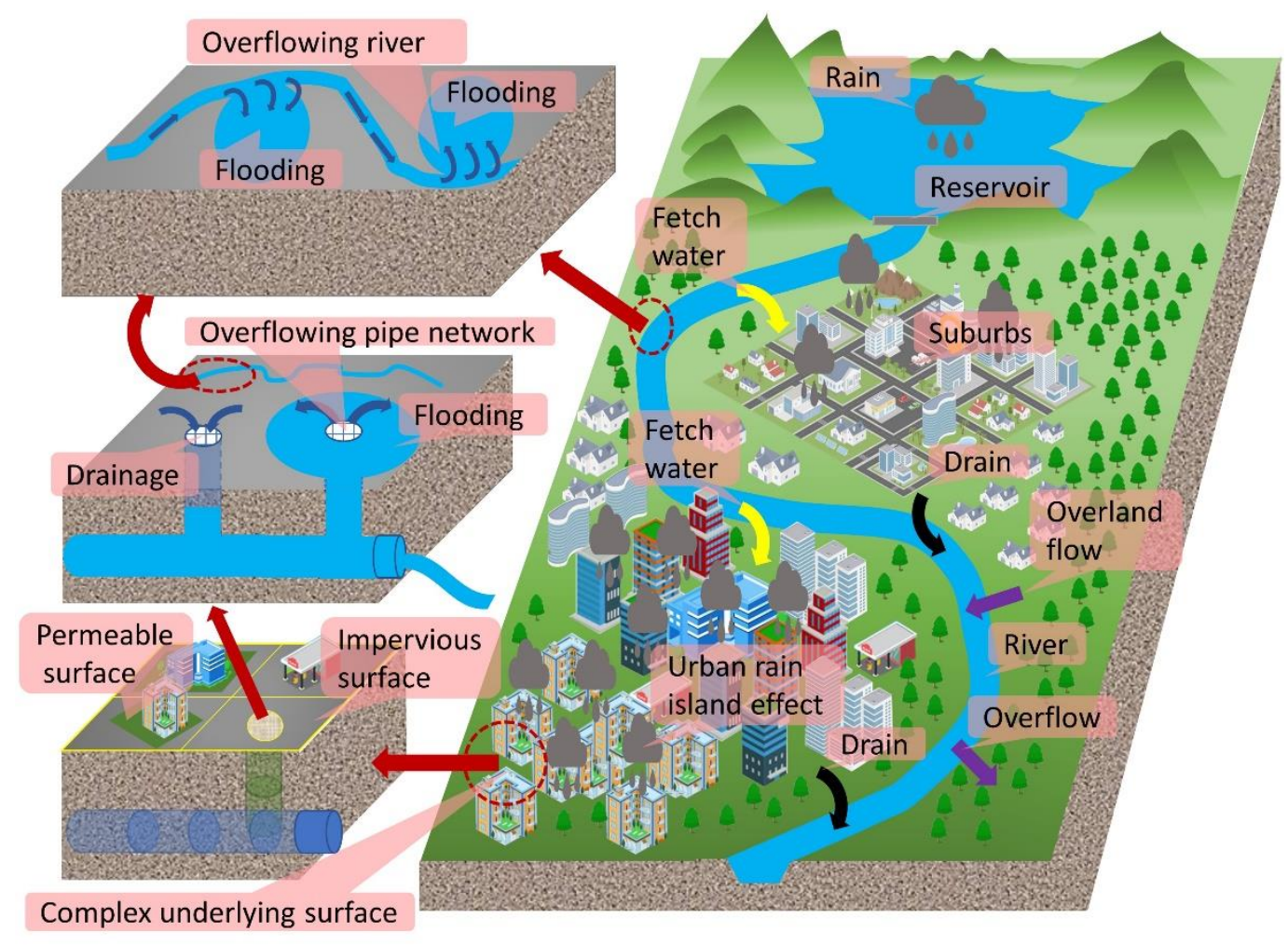

Figure 1. Schematic diagram of urban rain flood inundation principle.

\section{Materials and methods}

\subsection{Study site}

We selected Luoyang city center, in the northern Henan Province of China, as our 
Luoyang city center, which constitutes the northern part of Luoyang city, is a typical small basin city with an area of $803 \mathrm{~km}^{2}$, and is situated within the Yi-Luo River Basin.

The two rivers of Yi he and Luo he passed through the downtown area of Luoyang.

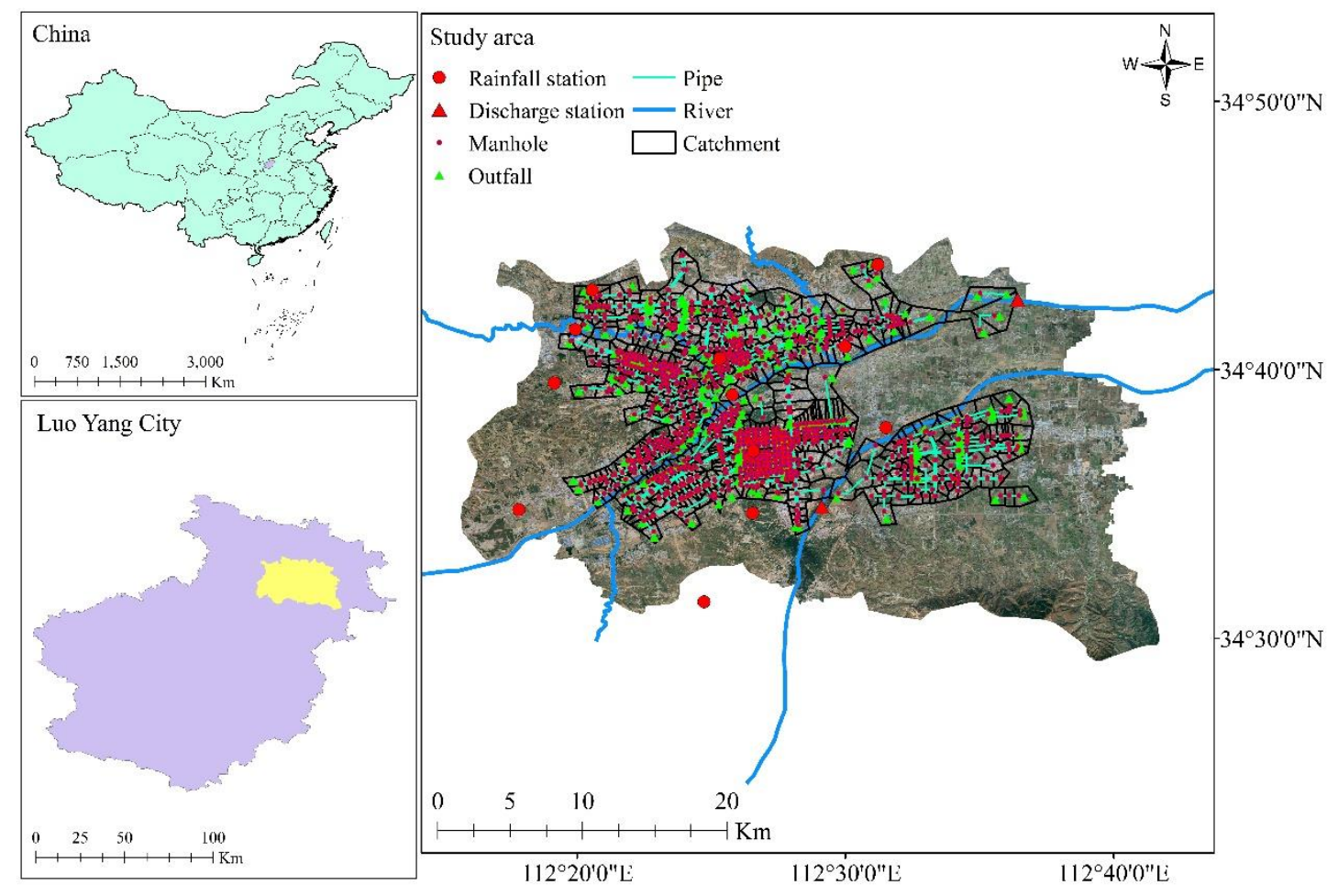

Figure 2. Study area

The annual average temperature and rainfall are $14.6^{\circ} \mathrm{C}$ and $600.2 \mathrm{~mm}$. And June to September accounted for $63.3 \%$ of the annual precipitation. Study area has a semiarid area with an average water surface evaporation of $1200 \mathrm{~mm}$ and an aridity index of 2.0. Luoyang city center is a highly urbanized area, containing numerous businesses, campuses, and residential areas. The coverage of impervious areas reaches $72 \%$.

Although Luoyang city center is a newly developed area, its sewer system is insufficient for its current drainage needs. Most of the sewer system is designed for oneor two-year return periods. Thus, inundation is a normal occurrence during rainstorms in Luoyang city center. In 2019, a rainstorm hit the entire Luoyang City, causing direct 
economic losses of \$9.693 million. Luoyang City experienced significant damage from that rainstorm and many streets were severely flooded. Therefore, it is a suitable site to study the characteristics of rainfall-induced inundations.

\subsection{Data availability and processing}

\subsubsection{Topographic data}

In this study, Digital elevation models (DEM) are from Geospatial Data Cloud (http://www.gscloud.cn/sources/accessdata/421?pid=302) with a grid size of $30 \mathrm{~m} \times 30$ $\mathrm{m}$ to be used in urban dynamic modeling. The building profiles were distinguished through high-resolution Google remote sensing images. Further, buildings were regarded as non-flooding zones. Here increased the height by $10 \mathrm{~m}$ at the corresponding position on the DEM. In this way, the Digital Surface models (DSM) used to construct the surface flow model was obtained. Thus, they were excluded from meshing to ensure that they were not modeled as flooding zones.

\subsubsection{Drainage system data}

The drainage system data, provided by the Luoyang Drainage Management Bureau, contained geographic and geometric information on the pipes, manholes, rivers, and storage areas (e.g., holding ponds). Rainwater and wastewater in the study area are drained separately. The diameters of the pipes ranged from 0.5 to $2.00 \mathrm{~m}$ and the depths of the manholes ranged from 1.00 to $5.00 \mathrm{~m}$. There are 5 rivers in the research region: the Yi, Luo, Chan, Jian and Ganshui rivers (Table 1). These rivers have been improved artificially a few years ago and most of their cross-sections are now rectangular. Thus, the rivers were set as rectangular open channels in the model. There are eight artificial 
139 lakes on study area, which were set as storage nodes in the model. Consequently, 3610

140 pipes and open channels, 4792 manholes, 161 outfalls, and eight storages were included

141 in the model (Fig. 2).

142

Table 1. Basic information of Yi, Luo, Chan, Jian and Ganshui rivers

\begin{tabular}{cccc}
\hline River name & $\begin{array}{c}\text { Channel length } \\
(\mathrm{km})\end{array}$ & $\begin{array}{c}\text { Number of river } \\
\text { sections }\end{array}$ & $\begin{array}{c}\text { Average distance } \\
\text { of section }(\mathrm{m})\end{array}$ \\
\hline Yi river & 23.2 & 32 & 725.0 \\
Luo river & 44.5 & 84 & 529.7 \\
Chan river & 10.4 & 31 & 322.6 \\
Jian river & 19.2 & 32 & 600.0 \\
Ganshui river & 7.6 & 16 & 475.0 \\
\hline
\end{tabular}

2.2.3. Rainstorm data

Two recorded historical rainstorms, Storm 1 and Storm 2 (Fig. 3), were used to

145 calibrate and evaluation the coupled model. These two rainstorms occurred on August

1464,2019 and August 6, 2019, respectively. The rainstorm data were obtained from the

147 China Meteorological Data Service Center (http://cdc.nmic.cn/home.do). 


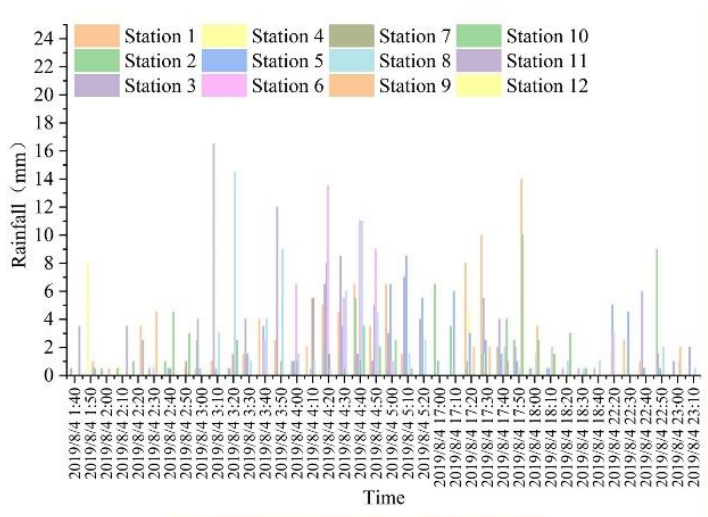

Storm 1: 20190804

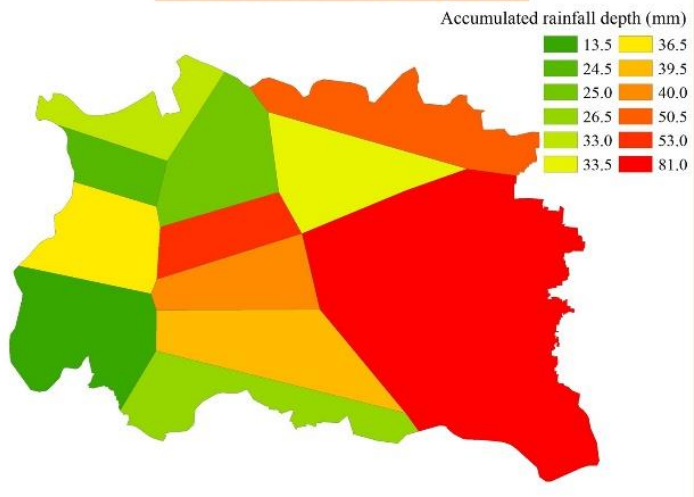

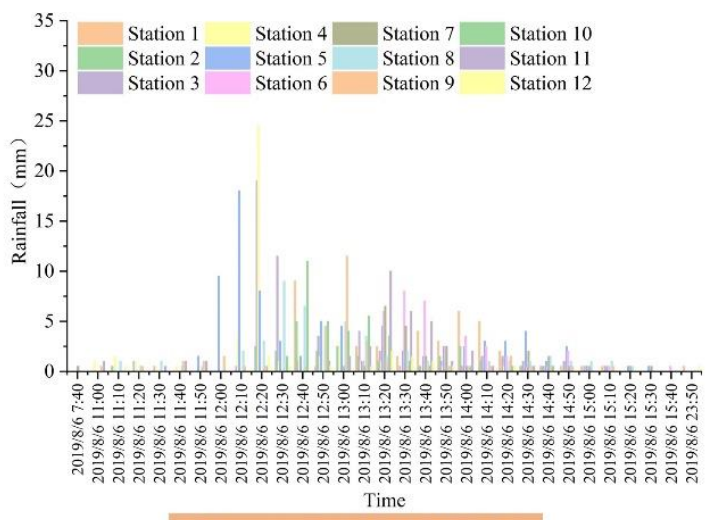

Storm 2: 20190806

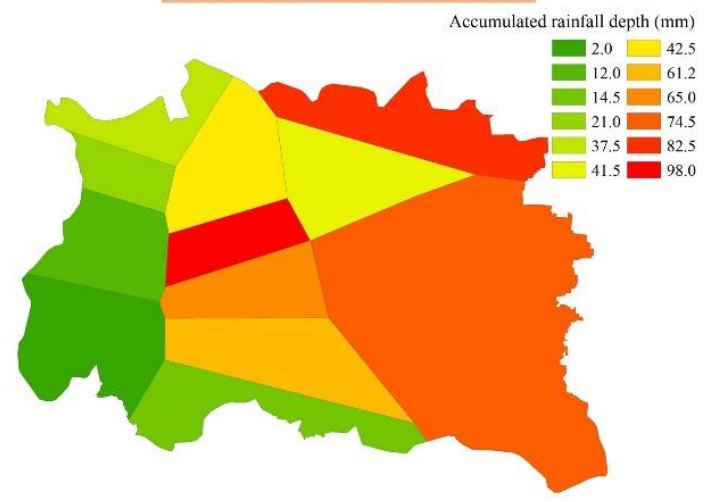

Figure 3. Hydrographs of the two historical rainstorms (August 4, 2019 and was set to $60 \mathrm{~min}, 120 \mathrm{~min}, 360 \mathrm{~min}$, and $720 \mathrm{~min}$ (Fig.4). We named these four rainstorms (Fig.4) as Pattern 1, Pattern 2, Pattern 3, and Pattern 4.

$$
q=\frac{3336(1+0.872 \operatorname{LgP})}{(t+14.8)^{0.884}}
$$



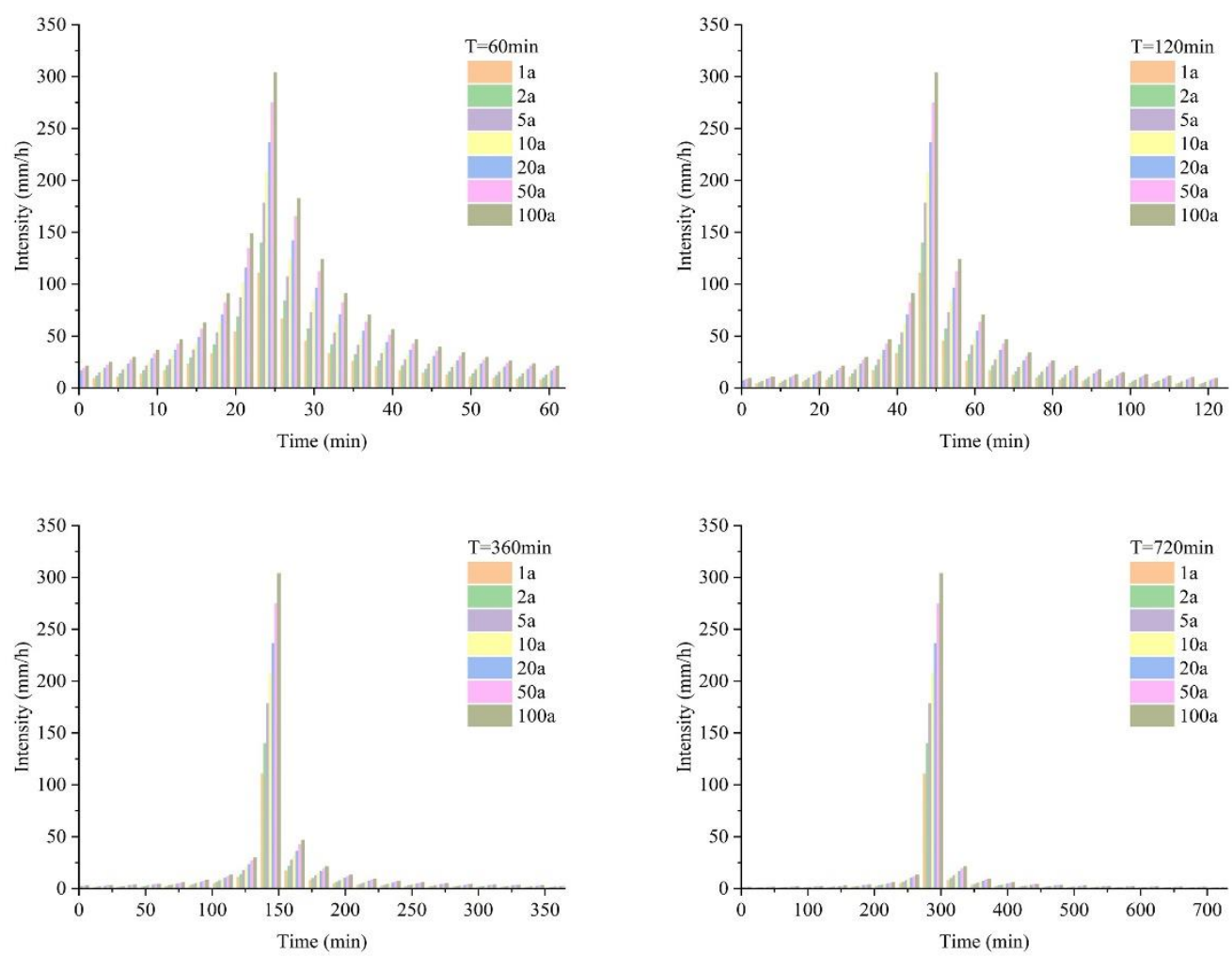

162

Figure 4. Synthetic hyetograph of four rainstorm patterns.

\subsection{D-2D Couples model}

We simultaneously simulated the flow dynamics in sewer networks, rivers, and on overland surfaces by coupling MIKE 11, MIKE 21 and MIKE Urban models. The three models were executed individually at every single time step, and then connected through appropriate linkages to exchange information obtained at suitable locations at the end of every time step ${ }^{24}$.

In general, flow exchange occurs at the connection between the surface flows and pipe or river flows. Thus, three types of linkages, including vertical, lateral, and longitudinal linkages, were implemented and studied here. The relationships between these three models and the three linkages are presented in Fig. 5. 


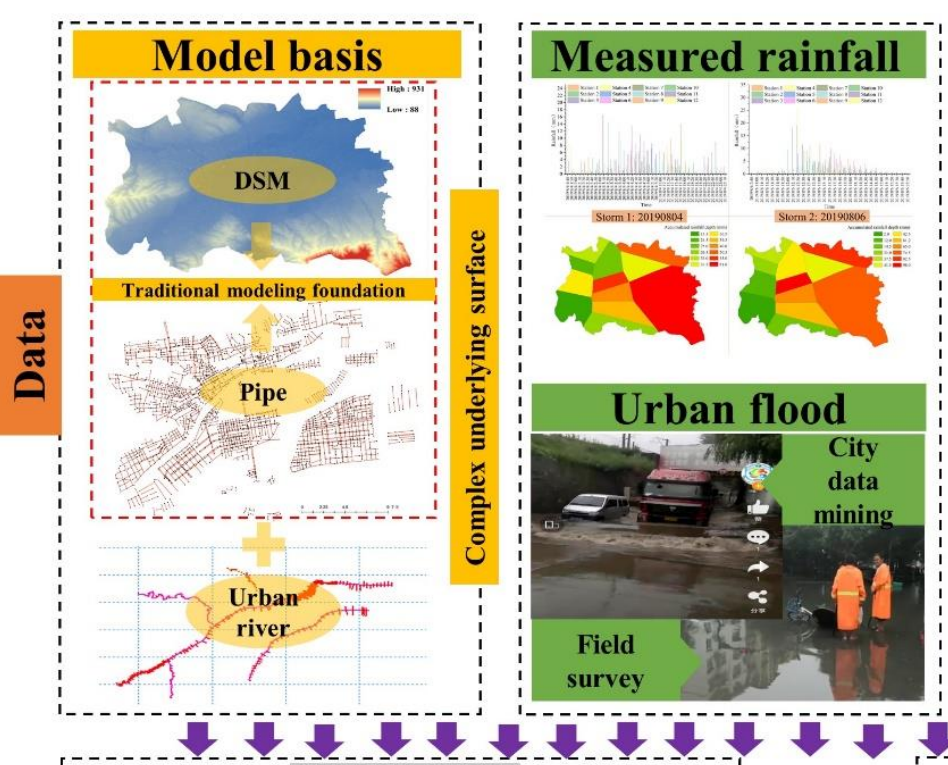

Submerged depth

1D model
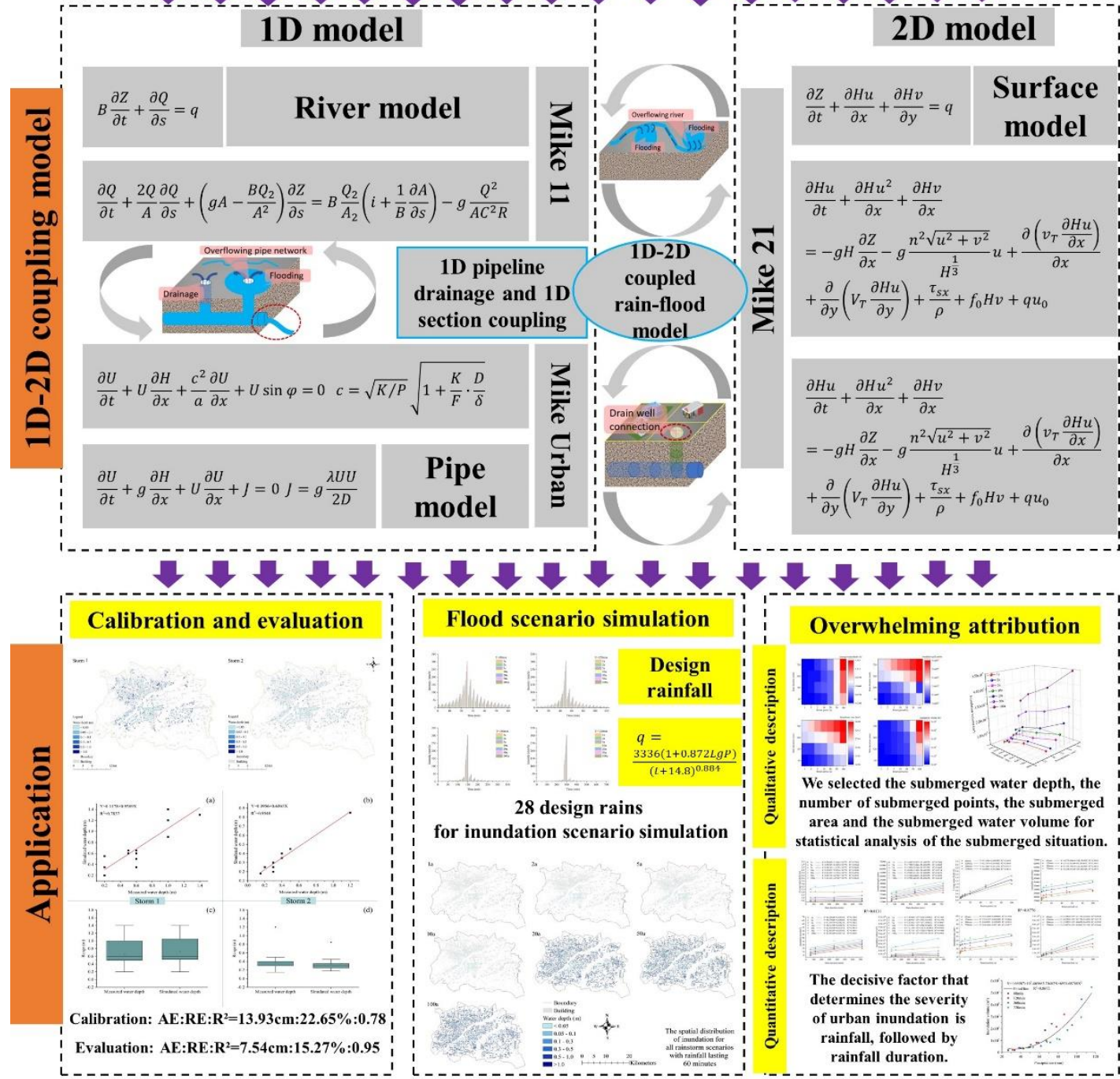

Figure 5. The process frame diagram of this study 


\subsubsection{MIKE 11 model}

Mike11 is a one-dimensional river and river network comprehensive simulation model $^{25}$. This research uses the hydrodynamic module of MIKE 11, which mainly uses the continuity equation of water flow and the equation of water flow motion, given the boundary conditions such as rainfall, soil type, river section and river channel roughness, and then the flow rate of the section is obtained through the equation Water level data information. The principle is to use the finite difference method for numerical solution ${ }^{26}$. The basic equations of the one-dimensional hydrodynamic model are as follows: Water flow continuity equation:

$$
B \frac{\partial Z}{\partial t}+\frac{\partial Q}{\partial s}=q
$$

Water flow equation:

$$
\frac{\partial Q}{\partial t}+\frac{2 Q}{A} \frac{\partial Q}{\partial s}+\left(g A-\frac{B Q_{2}}{A^{2}}\right) \frac{\partial Z}{\partial s}=B \frac{Q_{2}}{A_{2}}\left(i+\frac{1}{B} \frac{\partial A}{\partial s}\right)-g \frac{Q^{2}}{A C^{2} R}
$$

In the formula, $q$ is the side flow, $Q$ is the total flow, $s$ is the distance coordinate, $V$ is the average flow velocity of the section, $h$ is the water depth, $A$ is the area of the cross section, $i$ is the canal bottom slope, and $C$ is the Xie Cai coefficient. The onedimensional (1D) model is discretized by the finite difference method, and the difference format is the 6-point center Abbott-Ionescu format. The chasing method is used to solve the discrete equation ${ }^{27}$.

\subsubsection{MIKE 21 model}

MIKE 21 is the most versatile two-dimensional water physical, chemical or biological process simulation tool to date ${ }^{28}$. The HD-two-dimensional hydrodynamic module mainly used in this research: This module is used to simulate the changes in 
water level and water flow caused by various forces, including a wide range of hydraulic phenomena, and can be used for any two-dimensional with negligible stratification Simulation of free surface flow. Its mathematical principles are mainly continuous equations and momentum equations ${ }^{25}$.

The basic principles of the two-dimensional hydrodynamic calculation model are as follows:

$$
\text { Continuous equation: }
$$

$$
\frac{\partial Z}{\partial t}+\frac{\partial H u}{\partial x}+\frac{\partial H v}{\partial y}=q
$$

Momentum equation:

$$
\frac{\partial H u}{\partial t}+\frac{\partial H u^{2}}{\partial x}+\frac{\partial H v}{\partial x}=-g H \frac{\partial Z}{\partial x}-g \frac{n^{2} \sqrt{u^{2}+v^{2}}}{H^{\frac{1}{3}}} u+\frac{\partial\left(v_{T} \frac{\partial H u}{\partial x}\right)}{\partial x}+\frac{\partial}{\partial y}\left(V_{T} \frac{\partial H u}{\partial y}\right)+\frac{\tau_{s x}}{\rho}+
$$

$f_{0} H v+q u_{0}$

$$
\begin{gathered}
\frac{\partial H u}{\partial t}+\frac{\partial H u^{2}}{\partial y}+\frac{\partial H u v}{\partial x}=-g H \frac{\partial Z}{\partial x}-g \frac{n^{2} \sqrt{u^{2}+v^{2}}}{H^{\frac{1}{3}}} V+\frac{\partial\left(v_{T} \frac{\partial H v}{\partial x}\right)}{\partial x}+\frac{\partial}{\partial y}\left(V_{T} \frac{\partial H v}{\partial y}\right)+\frac{\tau_{s y}}{\rho}+ \\
f_{0} H u+q v_{0} \\
f_{0}=2 \omega_{0} \sin \varphi
\end{gathered}
$$

In the formula, $q$ is the intensity of the source and sink per unit area; $H$ is the water depth; $Z$ is the water level; $u$ and $V$ are the components of the vertical average velocity in the $x$ and $y$ directions respectively; $n$ is the roughness; $g$ is the acceleration of gravity; $V_{T}$ is the water flow. Turbulent diffusion coefficient; $f_{0}$ is the Coriolis force coefficient, $\omega_{0}$ is the rotation angular velocity of the earth, $\psi$ is the geographic latitude of the calculation area; $\rho$ is the current density; $u_{0}$ and $v_{0}$ are the component of the average depth of the source and sink velocity in the $x$ and $y$ directions; $\tau_{s x}$ and $\tau_{s y}$ respectively 
represents the $x$ and $y$ directions Wind stress on the water surface. In the calculation process, the mathematical model can be appropriately simplified according to the actual situation to ignore the influence of wind stress and the Earth's Coriolis force ${ }^{29}$.

The ADI line-by-line method is used to integrate the continuous and momentum equations of the two-dimensional model in time and space, and the discrete equations are solved by the catch-up method ${ }^{28}$.

\subsubsection{MIKE urban model}

Drainage pipes or covered channels in cities are usually in the state of open channel flow $^{30}$. With the increase of rainfall intensity, the flow rate of the drainage pipe increases, and the water level in the pipe gradually rises above the top of the pipe, changing from a pressureless flow state to a pressure flow state ${ }^{31}$. With the weakening of the rainfall intensity, the flow rate in the pipe decreases, and the water surface of the pipe gradually drops below the top of the pipe, and a pressureless or open flow appears. The pressureless flow and the pressure flow alternately, from the pressureless open flow to the pressure full flow, and then from the pressure full flow to the pressureless open flow $^{32}$. Pressureless flow and pressure flow are two completely different water flow states. The calculation principle of unpressured flow is the same-dimensional hydrodynamic model.

The calculation principle of pressurized drainage network is as follows: Water flow continuity equation:

$$
\begin{gathered}
\frac{\partial U}{\partial t}+U \frac{\partial H}{\partial x}+\frac{c^{2}}{a} \frac{\partial U}{\partial x}+U \sin \varphi=0 \\
c=\sqrt{K / P} \sqrt{1+\frac{K}{F} \cdot \frac{D}{\delta}}
\end{gathered}
$$


Water flow equation:

$$
\begin{gathered}
\frac{\partial U}{\partial t}+g \frac{\partial H}{\partial x}+U \frac{\partial U}{\partial x}+J=0 \\
J=g \frac{\lambda U U}{2 D}
\end{gathered}
$$

In the formula, $H$ is the head of the piezometer; $U$ is the flow velocity; $g$ is the acceleration of gravity; $c$ is the propagation velocity of the wave, $K$ is the bulk wood modulus of the liquid, $D$ is the pipe diameter, $\delta$ is the pipe wall thickness, and $E$ is the spring modulus of the pipe. $J$ is friction head loss, $\lambda$ is the head loss coefficient along the way $^{33}$.

\subsection{Model evaluation Indicator Selection}

\subsubsection{Absolute Error}

The absolute error $(A E)$ is the absolute value of the difference between the measured value and the true value. Here it refers to the absolute value of the difference between the simulated water depth of the model and the actual measured water depth. The mathematical expression is as follows:

$$
A E=\left|S_{i}-O_{i}\right|
$$

where $S_{i}$ and $O_{i}$ are the simulated and observed water depth at the $i_{t h}$ number ${ }^{34}$.

\subsubsection{Relative Error}

Relative error $(R E)$ refers to the value obtained by multiplying the ratio of the absolute error caused by the measurement to the measured (conventional) true value by $100 \%$, expressed as a percentage. Generally speaking, the relative error can better reflect the credibility of the measurement. It is mostly used in the evaluation of urban rain and flood models to indicate the credibility of the simulated value of flood peak discharge. It is described as follows: 


$$
R E=\frac{S_{i}-O_{i}}{O_{i}} \times 100 \%
$$

265

where $S_{i}$ and $O_{i}$ are the simulated and observed water depth at the $i_{t h}$ number ${ }^{35}$.

\subsubsection{The Coefficient of Determination}

The coefficient of determination $\left(R^{2}\right)$ is often used to describe the degree of fit between data. When $R^{2}$ is closer to 1 , it means that the reference value of the related equation is higher; on the contrary, when it is closer to 0 , it means that the reference value is lower. It is described as follows:

$$
R^{2}=\frac{\left[\sum_{i=1}^{n}\left(S_{i}-\bar{S}\right)\left(o_{i}-\bar{O}\right)\right]^{2}}{\sum_{i=1}^{n}\left(S_{i}-\bar{S}\right)^{2}\left(O_{i}-\bar{O}\right)^{2}}
$$

where $\mathrm{n}$ is the total number of measured data, $S_{i}$ is the simulated water depth for data point i, $O_{i}$ is the measured water depth for data point i, and is the averaged value of the measured water depth ${ }^{35}$.

\subsubsection{Nash-Sutcliffe efficiency}

The mathematical expressions of these metrics can be described as follows:

$$
N S E=1-\frac{\sum_{i=1}^{n}\left(Q_{0}-Q_{c}\right)^{2}}{\sum_{i=1}^{n}\left(Q_{0}-\overline{Q_{c}}\right)^{2}}
$$

where $Q_{0}\left(\mathrm{~m}^{3} / \mathrm{s}\right)$ and $Q_{c}\left(\mathrm{~m}^{3} / \mathrm{s}\right)$ represent the discharge of the observed and simulated hydrographs, respectively; $\overline{Q_{0}}$ is the mean value of the observed discharge, and $\mathrm{n}$ is the data points number. NSE measures the ability of the model to predict variables different from the mean, gives the proportion of the initial variance accounted for by the model, and ranges from 1 (perfect fit) to $-\infty$. Values closer to 1 provide more accurate predictions ${ }^{36}$. 


\section{Result}

\subsection{Coupled model calibration and evaluation}

Two recorded historical rainstorms, storms 1 and 2, were used to calibrate and

validate the coupled model (Fig.6). Due to data limitations, the calibration and validation criteria mainly focused on surface inundation depths and extent ${ }^{26}$. The traditional lumped hydrological model requires multiple flood process data to calibrate the model parameters to obtain the best model parameters on average ${ }^{36}$. However, the MIKE model is a distributed physical hydrological model. Due to its physical significance, theoretically, as long as the flood process used for parameter optimization is accurate and true, as long as a flood can select appropriate model parameters ${ }^{32}$. This is where the advantages of distributed physical hydrology lie, and the past application experience of the MIKE model has also proved this point. In fact, when selecting the flood process for parameter optimization, there is no need to determine the basis, as long as the flood process data is reasonable and conforms to the law of flow generation and convergence, and there is no requirement for single-peak or double-peak flood process. From the results of this article and the previous application of the MIKE model, the optimal model parameters for a flood can meet the accuracy requirements of different types of flood simulations ${ }^{25}$. 


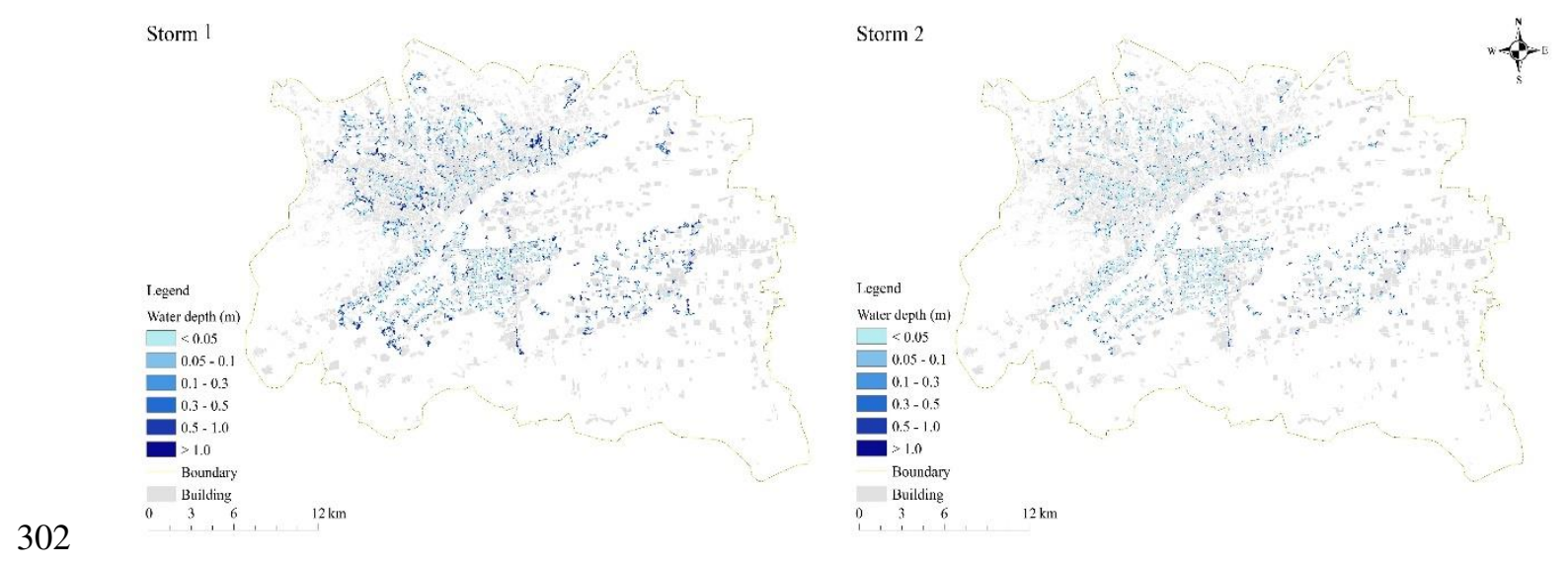

Figure 6. Spatial distributions of inundations from Storm 1 and Storm 2. 
Table 2. Table of simulation results of flooding depth of water accumulation point in storm 1

\begin{tabular}{|c|c|c|c|c|c|}
\hline $\begin{array}{l}\text { Site } \\
\text { number }\end{array}$ & Road section name & $\begin{array}{c}\text { Simulated water } \\
\text { depth } \\
\text { (m) }\end{array}$ & $\begin{array}{c}\text { Measured water } \\
\text { depth } \\
(\mathrm{m})\end{array}$ & $\begin{array}{l}\text { Absolute error } \\
\qquad(\mathrm{m})\end{array}$ & $\begin{array}{l}\text { Relative error } \\
(\%)\end{array}$ \\
\hline 1 & Anju Road Railway Bridge Culvert & 0.60 & 0.50 & 0.10 & 20.0 \\
\hline 2 & Luobai Road Anju Road Railway Bridge Culvert & 0.60 & 0.50 & 0.10 & 20.0 \\
\hline 3 & Low-lying area of Taxi Village, Hanhe Hui District & 0.65 & 0.60 & 0.05 & 8.3 \\
\hline 4 & $\begin{array}{c}\text { Taikang Road Wangcheng Avenue Intersection to } \\
\text { Xinyue Intersection }\end{array}$ & 0.65 & 0.50 & 0.05 & 10.0 \\
\hline 5 & Niepan Road Jiaozhi Railway Bridge Culvert & 0.35 & 0.60 & 0.25 & 41.7 \\
\hline 6 & Changchun Road, Jianxi District & 0.50 & 0.60 & 0.10 & 16.7 \\
\hline 7 & Wanda Intersection & 0.60 & 0.60 & 0.05 & 8.3 \\
\hline 8 & Sui-Tangcheng Road Longhai Railway Line Culvert & 0.20 & 0.20 & 0.01 & 5.0 \\
\hline 9 & $\begin{array}{c}\text { Guanlin Station Bridge, Erguang Expressway, Yibin } \\
\text { District }\end{array}$ & 0.55 & 0.20 & 0.35 & 175.0 \\
\hline 10 & Pingdeng Street Overpass, Chanhe District & 0.35 & 0.20 & 0.15 & 75.0 \\
\hline 11 & Houzaimen Street, Yiren Road & 1.20 & 1.00 & 0.20 & 20.0 \\
\hline 12 & Qiming East Road Jiaoliu Railway Bridge Culvert & 1.40 & 1.00 & 0.40 & 40.0 \\
\hline 13 & Yiren Road, New District & 1.20 & 1.00 & 0.20 & 20.0 \\
\hline 14 & East Huatan Overpass, Yanhe District & 0.90 & 1.00 & 0.10 & 10.0 \\
\hline 15 & Longmen Avenue, Longmen North Bridge & 1.30 & 1.40 & 0.10 & 7.1 \\
\hline 16 & Evergrande Oasis Section of East Zhongzhou Road & 0.60 & 0.50 & 0.10 & 20.0 \\
\hline
\end{tabular}


Table 3. Table of simulation results of flooding depth of water accumulation point in storm 2

\begin{tabular}{|c|c|c|c|c|c|}
\hline $\begin{array}{c}\text { Site } \\
\text { number }\end{array}$ & Road section name & $\begin{array}{l}\text { Simulated water } \\
\text { depth }(\mathrm{m})\end{array}$ & $\begin{array}{l}\text { Measured water } \\
\text { depth }(\mathrm{m})\end{array}$ & $\begin{array}{l}\text { Absolute error } \\
(\mathrm{m})\end{array}$ & $\begin{array}{c}\text { Relative erro } \\
(\%)\end{array}$ \\
\hline 1 & Anju Road Railway Bridge Culvert & 0.30 & 0.30 & 0.05 & 16.7 \\
\hline 2 & Luobai Road Anju Road Railway Bridge Culvert & 0.30 & 0.30 & 0.05 & 16.7 \\
\hline 3 & Low-lying area of Taxi Village, Chanhe District & 0.40 & 0.40 & 0.05 & 12.5 \\
\hline 4 & $\begin{array}{c}\text { Taikang Road Wangcheng Avenue Intersection to } \\
\text { Xinyue Intersection }\end{array}$ & 0.25 & 0.30 & 0.05 & 16.7 \\
\hline 5 & Niepan Road Jiaozhi Railway Bridge Culvert & 0.25 & 0.20 & 0.05 & 0.25 \\
\hline 6 & Changchun Road, Jianxi District & 0.25 & 0.20 & 0.05 & 0.25 \\
\hline 7 & Wanda Intersection & 0.35 & 0.40 & 0.05 & 12.5 \\
\hline 8 & Sui-Tangcheng Road Longhai Railway Line Culvert & 0.25 & 0.30 & 0.05 & 16.7 \\
\hline 9 & $\begin{array}{c}\text { Guanlin Station Bridge, Erguang Expressway, Yibin } \\
\text { District }\end{array}$ & 0.85 & 1.20 & 0.35 & 29.2 \\
\hline 10 & Pingping Street Overpass, Yanhe District & 0.30 & 0.30 & 0.05 & 16.7 \\
\hline 11 & Houzaimen Street, Yiren Road & 0.18 & 0.15 & 0.03 & 20.0 \\
\hline 12 & Qiming East Road Jiaoliu Railway Bridge Culvert & 0.45 & 0.50 & 0.05 & 10.0 \\
\hline 13 & Yiren Road, New District & 0.20 & 0.30 & 0.10 & 33.3 \\
\hline 14 & East Huatan Overpass, Yanhe District & 0.90 & 1.00 & 0.10 & 10.0 \\
\hline 15 & Longmen Avenue, Longmen North Bridge & 1.30 & 1.40 & 0.10 & 7.1 \\
\hline 16 & Evergrande Oasis Section of East Zhongzhou Road & 0.60 & 0.50 & 0.10 & 20.0 \\
\hline
\end{tabular}


of 16 survey points in 2 historical storms and flood events (Table.2 and Table.3). The

311 average relative error of the calibration simulated water depth was $22.65 \%$, and the

312 average absolute error was $13.93 \mathrm{~cm}$; the average relative error of the verified simulated

313 water depth was $15.27 \%$, The average absolute error is $7.54 \mathrm{~cm}$.

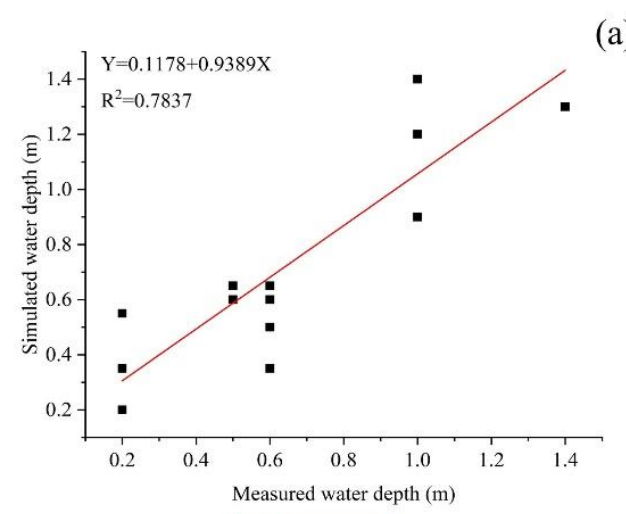

(a)

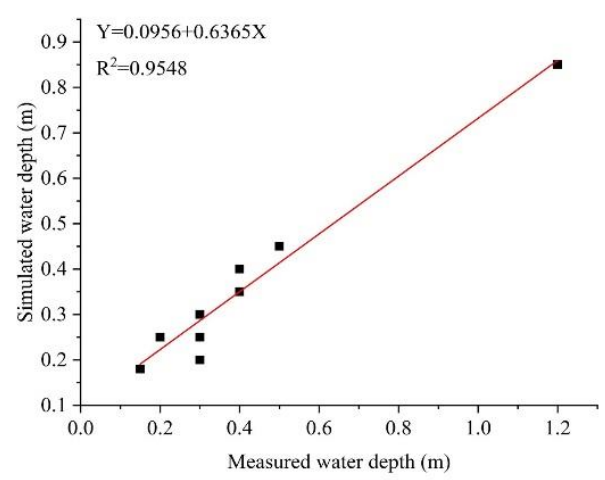

(b)

Storm 1

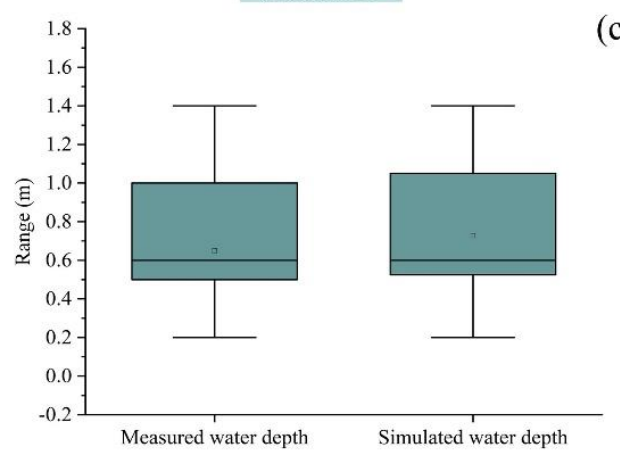

(c)

Storm 2

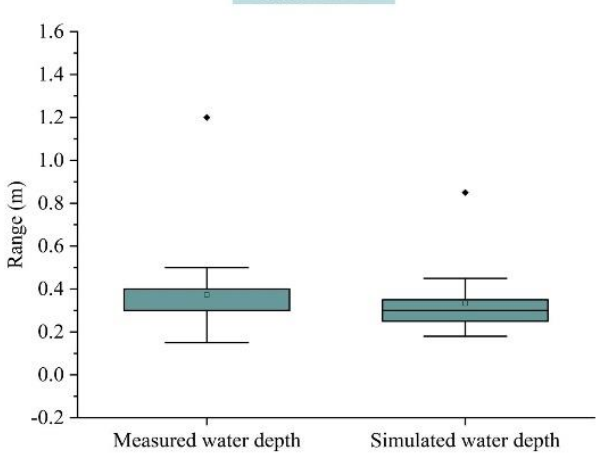

(d)

Figure 7. Comparison of simulated water depth and measured water depth of

The $R^{2}$ of the simulated and measured water depths of the 16 water accumulation points in the calibration period was 0.7837 , and the $R^{2}$ in the verification period was 0.9548 . The overall simulation results during the calibration period are all within a reasonable range, but there is an abnormal value during the verification period. The water 
accumulation point is the No. water accumulation point. The measured water depth at this point is 1.20 meters, the simulated water depth is 0.85 meters, and the $A E$ is 0.35 meters. But $R E$ is $29.2 \%$, which is also within a reasonable range.

For the reliability of the results, this study verified the simulated flow of the river network model. The results are shown in Figure 8.
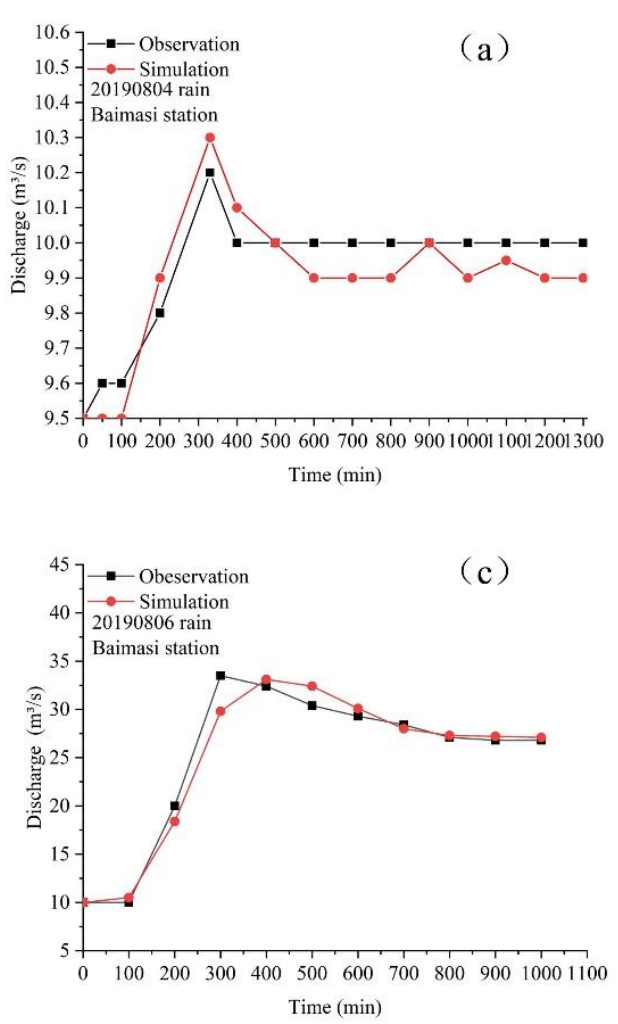
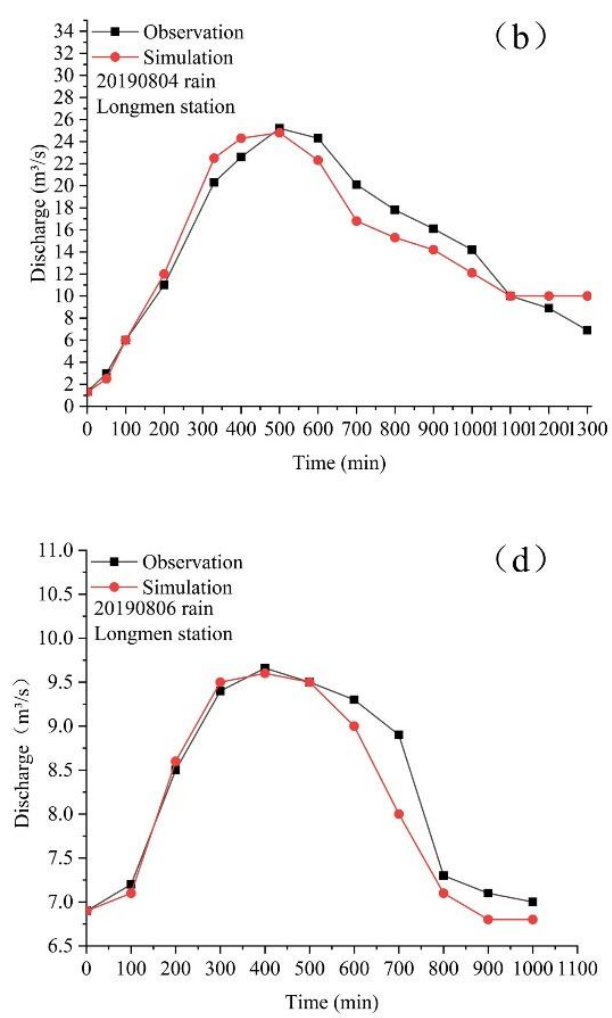

Figure 8. Comparison of simulated discharge and observed discharge of Storm 1 and Storm 2: (a) Discharge calibration of 20190804 rain in Baimasi station; (b) Discharge calibration of 20190804 rain in Longmen station; (c) Discharge evaluation of 20190806 rain in Baimasi station; (d) Discharge evaluation of 20190806 rain in Longmen station 
the NSE during the simulation verification period for Baimasi Station and Longmen Station in 20190806 were 0.96 and 0.91 respectively; therefore, the model simulation results are considered to be good.

\subsection{Inundation result under four different rainstorm patterns}

To explore the relationship between the amount of urban flood inundation on the amount of rainfall and the duration of rainfall, we designed the return periods of $1 \mathrm{a}, 2 \mathrm{a}$, 5a, 10a, 20a, 50a, 100a, and the rainfall duration of $60 \mathrm{~min}, 120 \mathrm{~min}, 360 \mathrm{~min}, 720 \mathrm{~min}$. 28 rainstorms were simulated and calculated by storm-inundation. The spatiotemporal results are presented in Sections 3.2.1-3.2.3. From the results of flooding locations, the flooded area of densely constructed central urban areas is larger than that of suburban areas. The greater the amount of rainfall during the event, the greater the submerged area and water depth ${ }^{37}$. This explains the frequent occurrence of flooding disasters when the city encounters rainfall. This poses a serious hazard to the safety of urban traffic, pedestrians and vehicles. Therefore, effectively simulating the degree of inundation by heavy rains and floods in urban areas has important practical significance for urban flood control and disaster reduction and traffic emergency management, and can provide important scientific and technological support for solving urban waterlogging problems $^{38}$. 

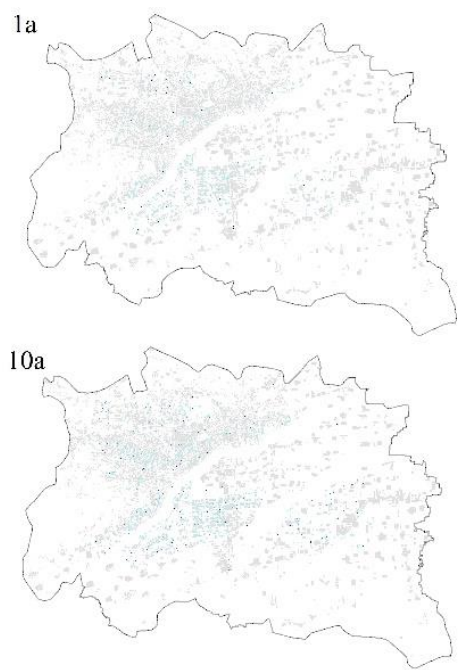

$100 \mathrm{a}$

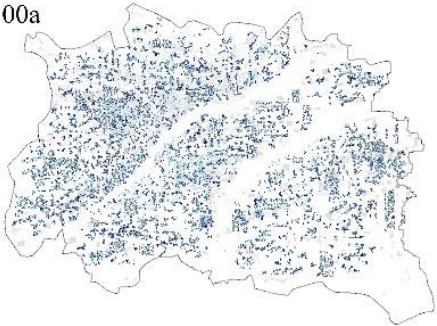

$2 a$

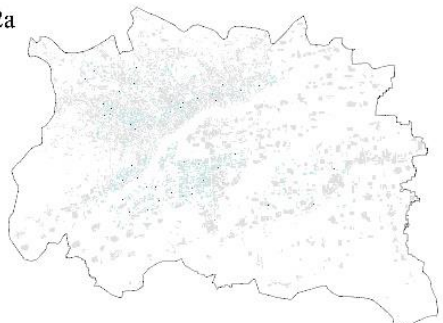

$20 \mathrm{a}$
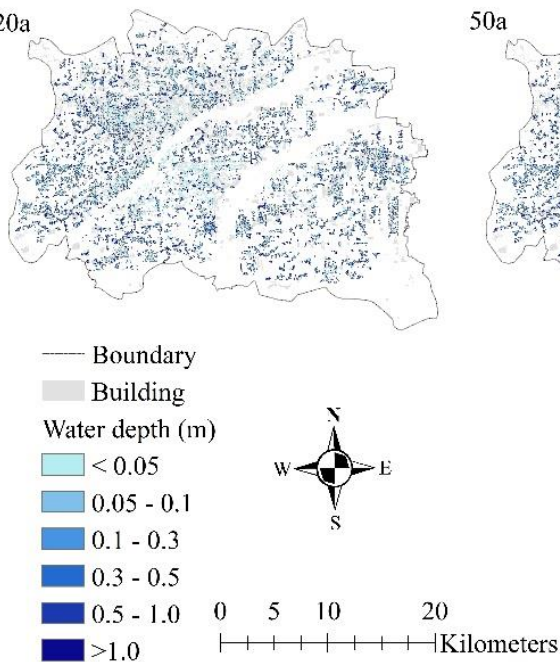

5

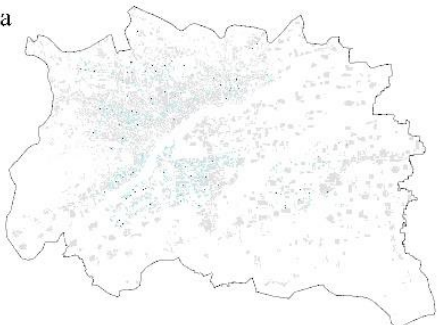

$50 \mathrm{a}$

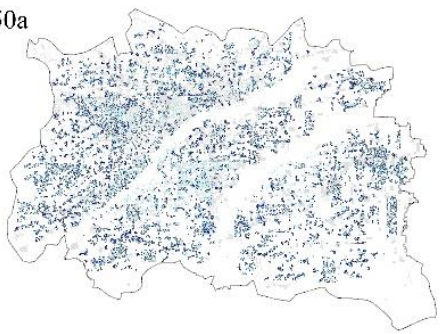

The spatial distribution of inundation for all rainstorm scenarios with rainfall lasting 60 minutes

Figure 9. Spatial distributions of inundation for $60 \mathrm{~min}$ rainstorm scenarios.
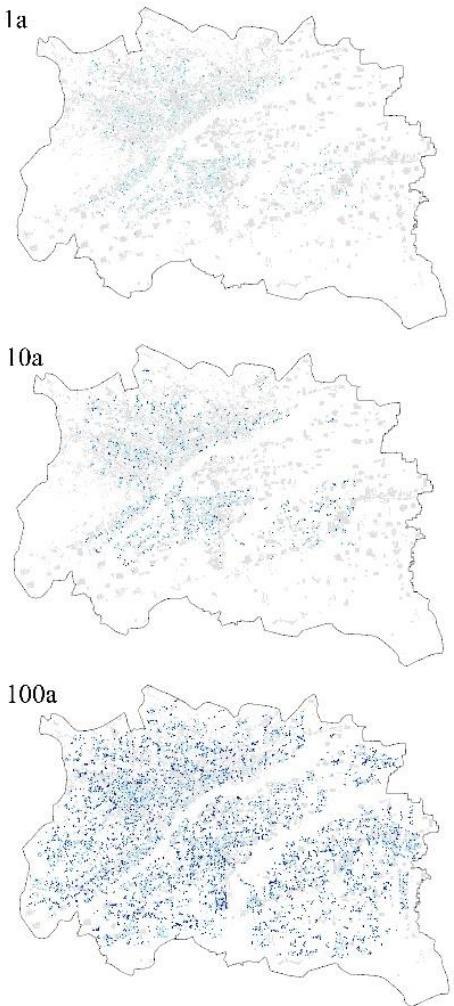

$2 \mathrm{a}$
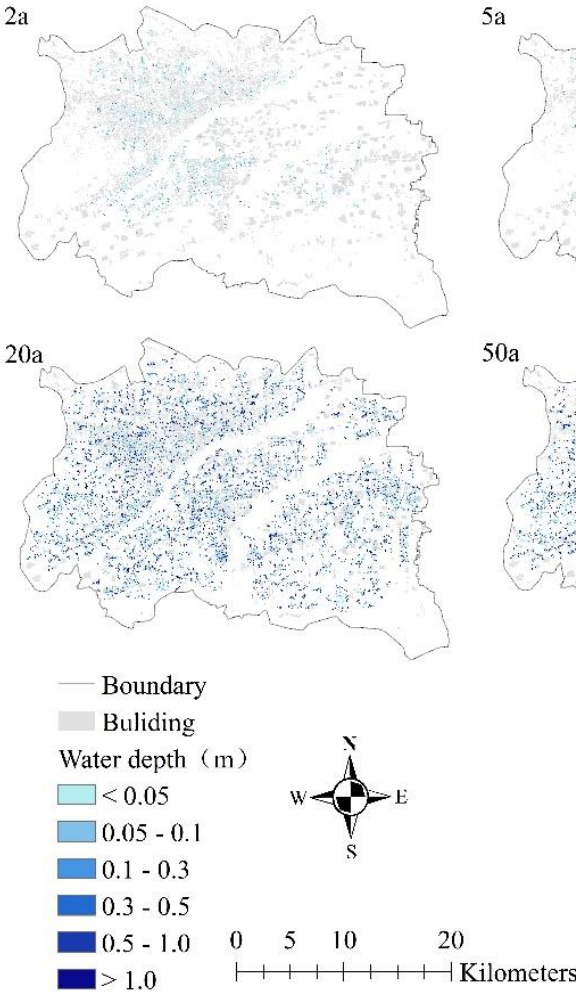

$5 \mathrm{a}$

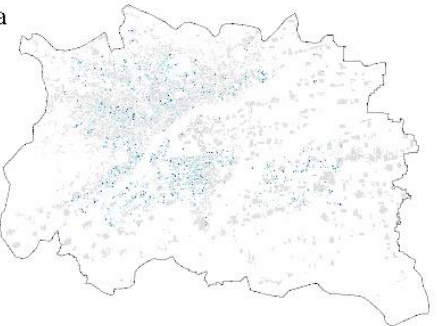

$50 \mathrm{a}$

The spatial distribution of inundation for all rainstorm scenarios with rainfall lasting 120 minutes

Figure 10. Spatial distributions of inundation for 120min rainstorm scenarios. 
1a

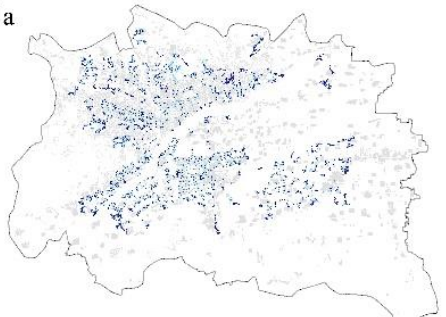

10a

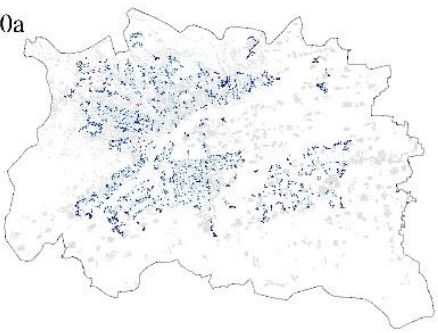

$100 \mathrm{a}$

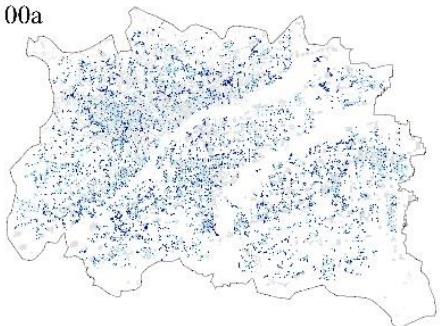

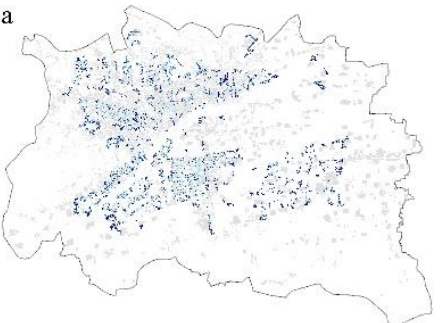
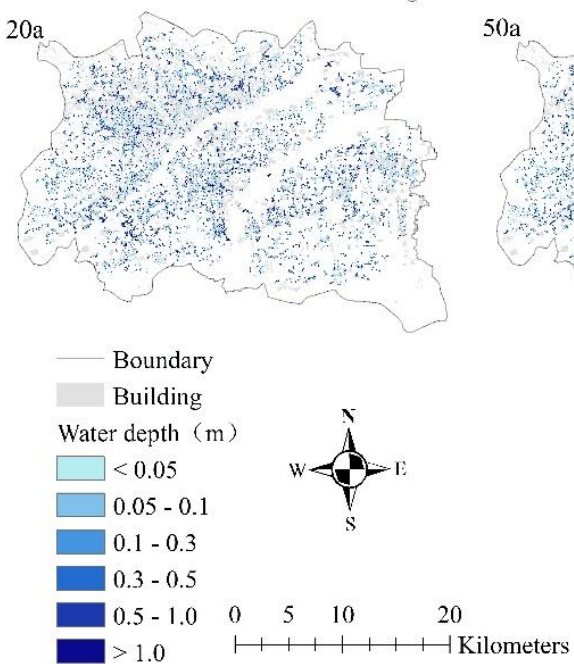

$5 \mathrm{a}$

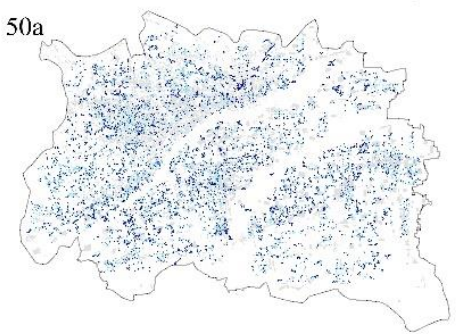

The spatial distribution of inundation for all rainstorm scenarios with rainfall lasting 360 minutes

Figure 11. Spatial distributions of inundation for 360min rainstorm scenarios.

1

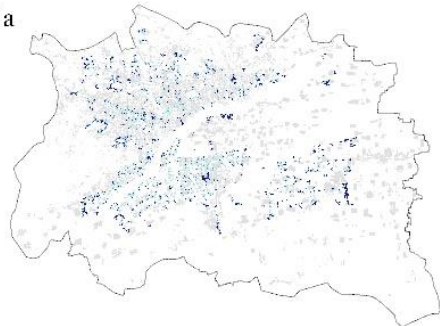

$10 \mathrm{a}$
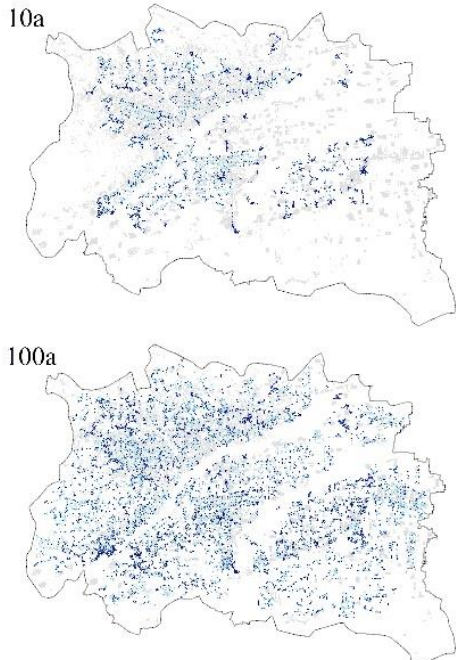

$2 a$

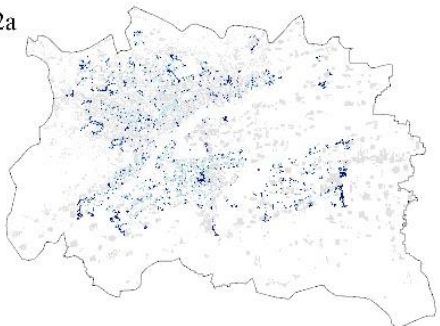

$20 \mathrm{a}$

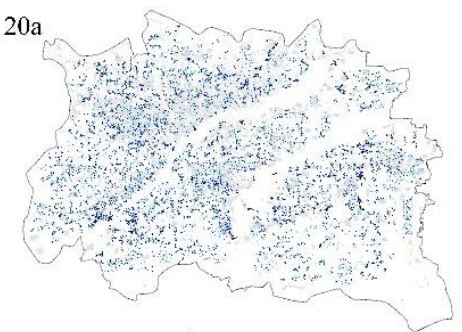

Boundary

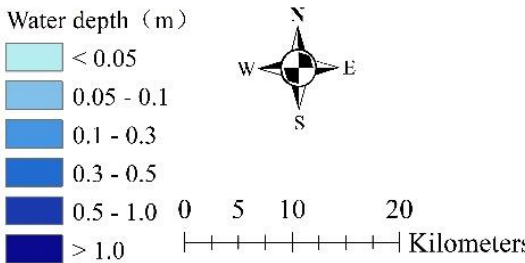

$5 a$

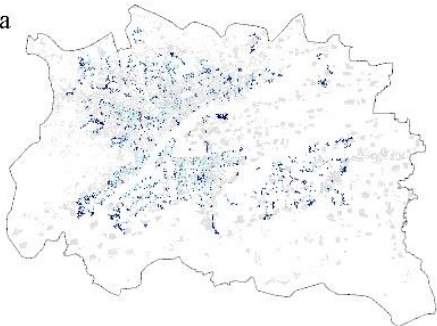

$50 \mathrm{a}$

The spatial distribution of inundation for all rainstorm scenarios with rainfall lasting 720 minutes

Figure 12. Spatial distributions of inundation for $720 \mathrm{~min}$ rainstorm scenarios. 


\begin{tabular}{|c|c|c|c|c|c|c|c|}
\hline Rain duration & $1 \mathrm{a}$ & $2 a$ & $5 \mathrm{a}$ & 10a & $20 \mathrm{a}$ & $50 \mathrm{a}$ & 100a \\
\hline $60 \mathrm{~min}$ & 1804911.66 & 1941154.2 & 3244379.67 & 4553029.98 & 8109544.59 & 18603459.18 & 24064675.2 \\
\hline $120 \mathrm{~min}$ & 2091859.56 & 3674307.24 & 6409150.11 & 8108518.32 & 9922175.64 & 21460579.2 & 31751228.07 \\
\hline $360 \mathrm{~min}$ & 3943031.4 & 4255403.85 & 5380177.77 & 8371173.33 & 10816143.84 & 22848784.38 & 44463856.5 \\
\hline $720 \mathrm{~min}$ & 3875545.08 & 4327303.77 & 8824576.32 & 11479946.49 & 18666670.05 & 29493651.6 & 54559375.68 \\
\hline
\end{tabular}

\subsubsection{Total inundation volumes}

We know that the maximum amount of inundated water is an important indicator to measure urban flood disasters. Generally speaking, the greater the maximum amount of inundated water, the more serious the urban flooding.

Table 4 presents the peak inundation volumes in each rainstorm, which ranged from $1804911.66 \mathrm{~m}^{3}$ to $24064675.2 \mathrm{~m}^{3}, 2091859.56 \mathrm{~m}^{3}$ to $31751228.07 \mathrm{~m}^{3}, 3943031.4$ $\mathrm{m}^{3}$ to $44463856.5 \mathrm{~m}^{3}$, and $3875545.08 \mathrm{~m}^{3}$ to $54559375.68 \mathrm{~m}^{3}$ for patterns $1,2,3$, and 4. The 28 rainfall scenarios set will all be flooded, and the amount of flooded water shows a trend of increasing with the increase of rainfall duration and return period. respectively. under the condition that the return period is 1 to 2 years, inundation will also occur, which shows that the urban drainage capacity is insufficient, which is also one of the direct causes of urban waterlogging. (Fig.13)

\subsubsection{Inundation positions and depths}

Cities, especially central cities, have concentrated dense buildings and populations.

Once urban flooding occurs, it will cause inevitable losses. Therefore, it is particularly important to simulate the spatial distribution of urban inundation scenarios.

Fig. 9-12 shows the submerged space distribution under four rain patterns, which highlights the differences in in the degree of inundation, and spatial distribution. Even 
during the same return period, there were considerable differences in the inundation extent between different rain duration. The overall trend is that as the rainfall duration increases, the submerged water depth and submerged area become larger. The inundation extents of Pattern 2 were close to those of Pattern 3, and Pattern 3 were close to those of Pattern 4. (Fig.13)

Table 5 presents the average submerged depth in each rainstorm, which ranged from $0.1242 \mathrm{~m}$ to $1.0040 \mathrm{~m}, 0.1246 \mathrm{~m}$ to $1.2123 \mathrm{~m}, 0.1635 \mathrm{~m}$ to $1.2425 \mathrm{~m}$, and 0.1564 $\mathrm{m}$ to1.4817 $\mathrm{m}$ for patterns $1,2,3$, and 4 . The results show that the longer the rainfall duration, the greater the average submerged depth. The greater the rainfall return period,

389 the greater the average submerged depth. This result is consistent with the amount of 390 submerged water. (Fig.13)

Table 5. Average submerged depth of all the rainstorm scenarios. Average 392 submerged depth (m)

\begin{tabular}{cccccccc} 
Return period & $1 \mathrm{a}$ & $2 \mathrm{a}$ & $5 \mathrm{a}$ & $10 \mathrm{a}$ & $20 \mathrm{a}$ & $50 \mathrm{a}$ & $100 \mathrm{a}$ \\
\hline Rain duration & & & & & & & \\
\hline $60 \mathrm{~min}$ & 0.1242 & 0.1245 & 0.1901 & 0.2514 & 0.4039 & 0.8014 & 1.0040 \\
$120 \mathrm{~min}$ & 0.1246 & 0.2108 & 0.3179 & 0.3826 & 0.4108 & 0.8408 & 1.2123 \\
$360 \mathrm{~min}$ & 0.1635 & 0.1731 & 0.2101 & 0.3211 & 0.3946 & 0.7769 & 1.2425 \\
$720 \mathrm{~min}$ & 0.1564 & 0.1577 & 0.2968 & 0.3623 & 0.5635 & 0.8365 & 1.4817 \\
\hline
\end{tabular}

\subsubsection{Inundation area}

After the occurrence of urban waterlogging, the submerged area is also one of the

395 key indicators to measure its severity. Table 6 presents the inundation area in each

396 rainstorm, which ranged from $14.5323 \mathrm{~km}^{2}$ to $23.9688 \mathrm{~km}^{2}, 16.7886 \mathrm{~km}^{2}$ to 26.1909

$397 \mathrm{~km}^{2}, 24.1164 \mathrm{~km}^{2}$ to $35.7858 \mathrm{~km}^{2}$, and $24.7797 \mathrm{~km}^{2}$ to $36.8217 \mathrm{~km}^{2}$ for patterns $1,2,3$, 398 and 4. Considering the spatial distribution (Fig.9-12), the flooding situation is more 
serious in densely constructed areas, and the flooding area is relatively large.

400

Table 6. Inundation area of all the rainstorm scenarios. Inundation area $\left(\mathrm{km}^{2}\right)$

\begin{tabular}{cccccccc}
\hline $\begin{array}{c}\text { Return period } \\
\text { Rain duration }\end{array}$ & 1a & $2 \mathrm{a}$ & $5 \mathrm{a}$ & $10 \mathrm{a}$ & $20 \mathrm{a}$ & $50 \mathrm{a}$ & $100 \mathrm{a}$ \\
\hline $60 \mathrm{~min}$ & 14.5323 & 15.5916 & 17.0667 & 18.1107 & 20.0781 & 23.2137 & 23.9688 \\
$120 \mathrm{~min}$ & 16.7886 & 17.4303 & 20.1609 & 21.1932 & 24.1533 & 25.5240 & 26.1909 \\
$360 \mathrm{~min}$ & 24.1164 & 24.5835 & 25.6077 & 26.0703 & 27.4104 & 29.4102 & 35.7858 \\
$720 \mathrm{~min}$ & 24.7797 & 27.4401 & 29.7324 & 31.6863 & 33.1263 & 35.2584 & 36.8217 \\
\hline
\end{tabular}

402 out in the downtown area of Luoyang. We selected the submerged water depth, the

403 number of submerged points, the submerged area and the submerged water volume for

404 statistical analysis of the submerged situation (Fig.13). The study found that these four

405 indicators are closely related to the rainfall return period and rainfall duration, and they

406 all show a good linear relationship. The average correlation coefficient with the rainfall

407 return period is 0.8776 (Fig. 14), and the average correlation coefficient with the rainfall

408 duration is 0.8131 (Fig.15). Therefore, it is concluded that the decisive factor that

409 determines the severity of urban inundation is rainfall, followed by rainfall duration. 

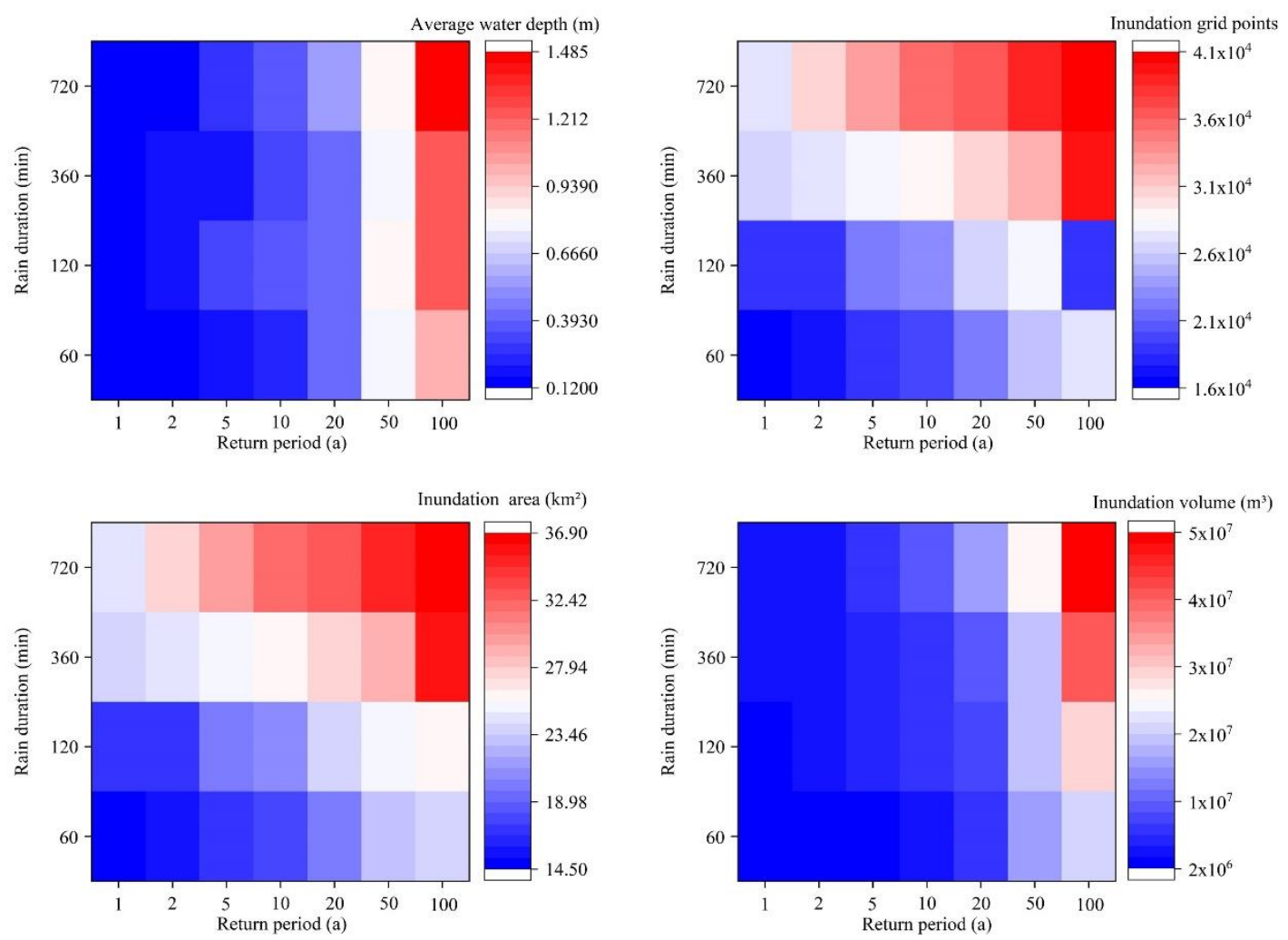

Figure 13. (a)The relationship between the average submerged water depth and

412 the return period and duration of rainfall. (b)The relationship between the number of

413 submerged grid points and the rainfall return period and rainfall duration. (c)The

414 relationship between submerged area and rainfall return period and rainfall duration.

415 (d)The relationship between submerged water volume and rainfall return period and rainfall duration. 

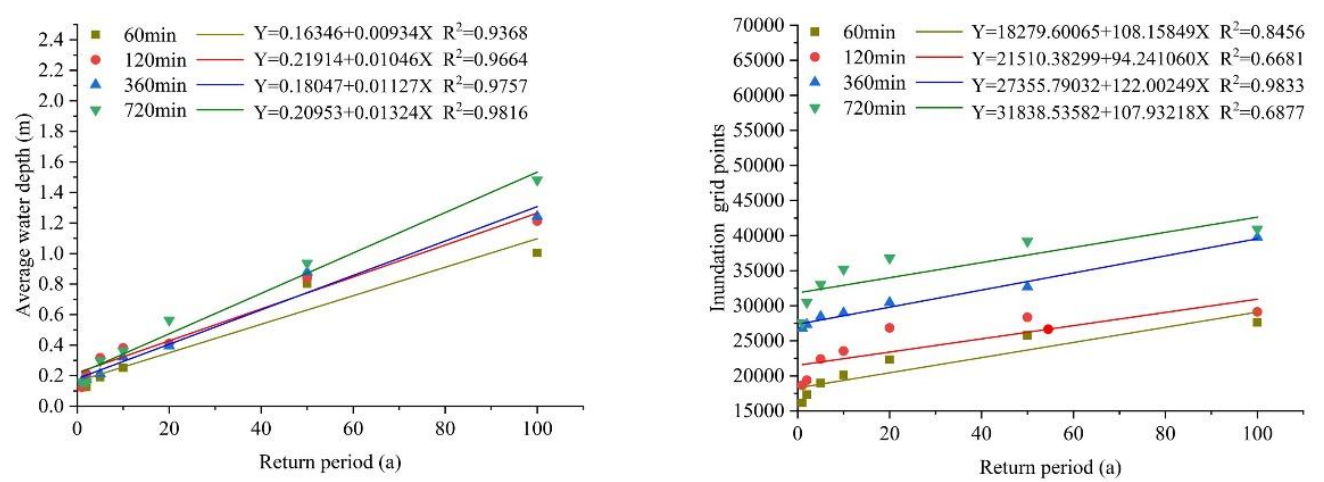

$\mathrm{R}^{2}=0.8776$
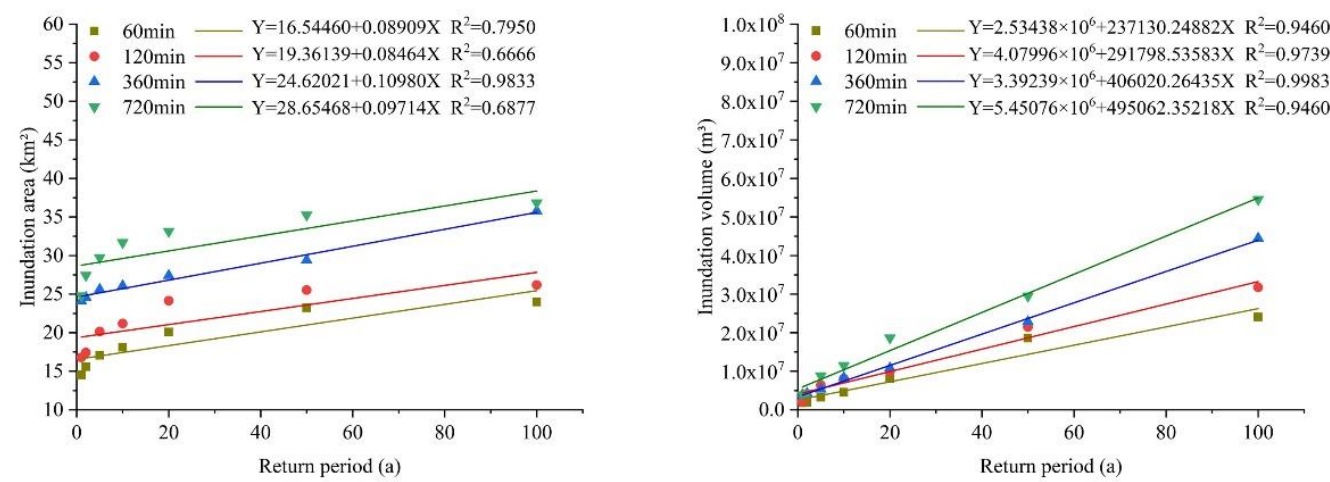

Figure 14. Trend chart of relationship between submerged water depth,

submerged grid points, submerged area, submerged water volume and return period.

421 (The return period and the four submergence indicators are linearly correlated, with an 


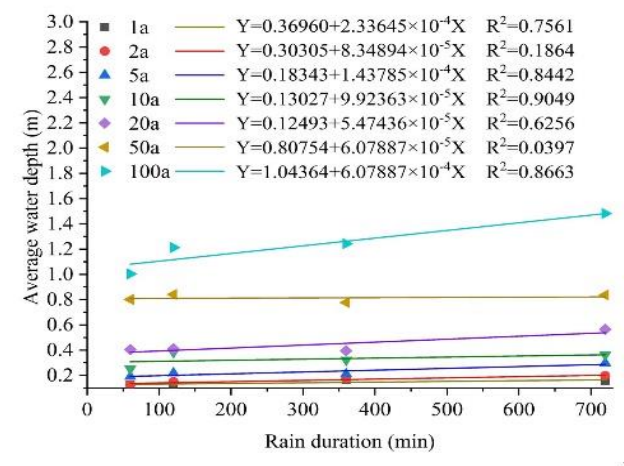

$\mathrm{R}^{2}=0.8131$

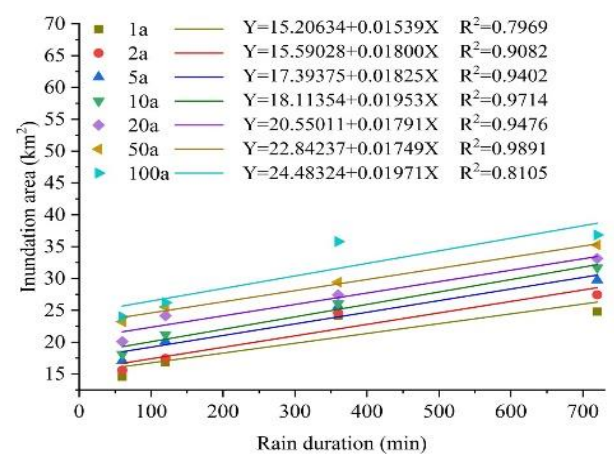

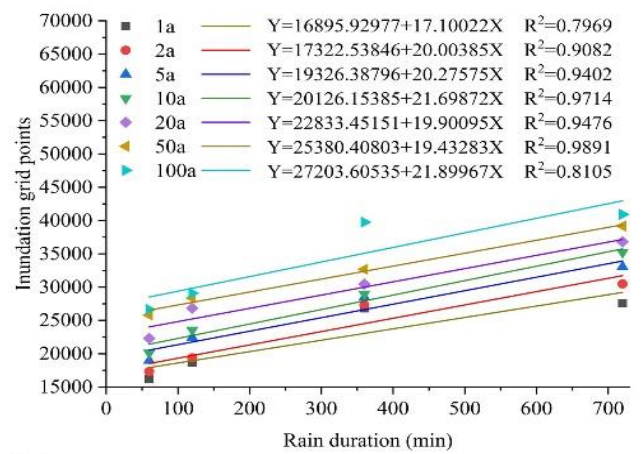

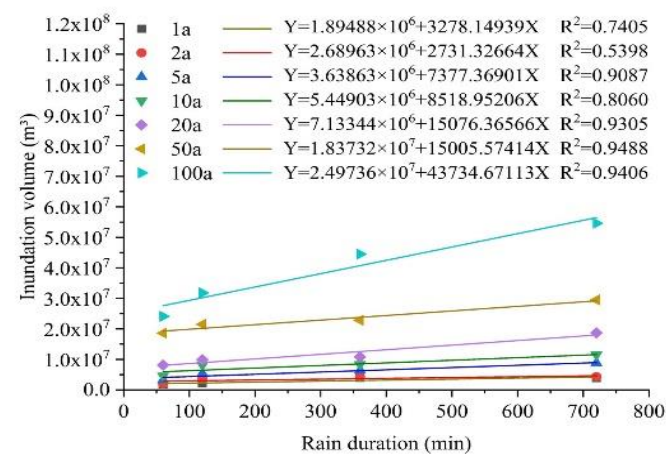

Figure 15. Trend chart of relationship between submerged water depth, submerged grid points, submerged area, submerged water volume and rain duration.

(The rain duration and the four submergence indicators are linearly correlated, with an average $R^{2}$ of 0.8131 .)

\section{Discussion}

\subsection{The rationality of coupling model construction}

As we all know, a city is a region, not a closed watershed. Therefore, when considering the problem of inland river overflow and waterlogging, since the upstream and downstream of the river are considered as the boundary of the city, it is necessary to pay attention to whether the boundary condition input of the upper and lower rivers is in line with reality ${ }^{27,39}$. In this study, the urban inland river system is considered, the upstream uses the measured flow as input, and the downstream uses the measured flow as output. The flooding of the river is jointly determined by the beware of elevation and 
heavy rain. Secondly, the model constructed by this research adopts the two-by-two connection method for the coupling of the drainage network, river, and surface, which is in line with the actual situation. The MIKE model is a distributed hydrological model with full physical meaning. Therefore, the parameter calibration only needs to adjust the time step to ensure that the model calculation results do not diverge $\mathrm{e}^{22}$. The measured water depth is compared with the simulated water depth to verify and achieve better accuracy. Therefore, the coupling model constructed in this study is reasonable ${ }^{33}$.

All inland rivers in Luoyang have been artificially treated. The shape of the rivers is regular, and the bank slope protection is mostly a single building material. This also reduces the computational complexity of the model and indirectly improves the simulation accuracy.

\subsection{Relationship between inundation volume and rainfall duration}

In the previous conclusion part, it is concluded that the decisive factor affecting the severity of urban inundation is the amount of rainfall, the second is the rainfall duration. Therefore, we analyze the correlation between the rainfall and the rainfall duration of the 28 design rains, the two main factors affecting inundation and the amount of inundation.

As shown in Figure 16, there is no doubt that the greater the rainfall, the greater the amount of flooding. However, Figure 16 also shows a trend that the longer the rainfall duration, the greater the amount of inundation, which is consistent with the analysis in the conclusion part, but it is different from the common-sense conclusion that "short duration and heavy rainfall cause serious urban waterlogging disasters"32-33, 
even in contrast. We also conducted detailed and rigorous discussion and research on this. In the study, we designed 28 rainfall using the Chicago rain pattern and used it as the rainfall input of the coupling model. In order to avoid the complexity of the research results, we uniformly set the rain front coefficient to 0.4 . That is to say, the proportion of the rain fronts of 28 rains is the same, which leads to the longer the rain lasts, the more prominent the rain peaks, and the more concentrated most of the rainfall of a rain.

This leads to a trend that the longer the rainfall lasts, the greater the amount of flooding. In fact, this is not inconsistent with the common-sense conclusion mentioned earlier, and even indirectly confirms this conclusion.

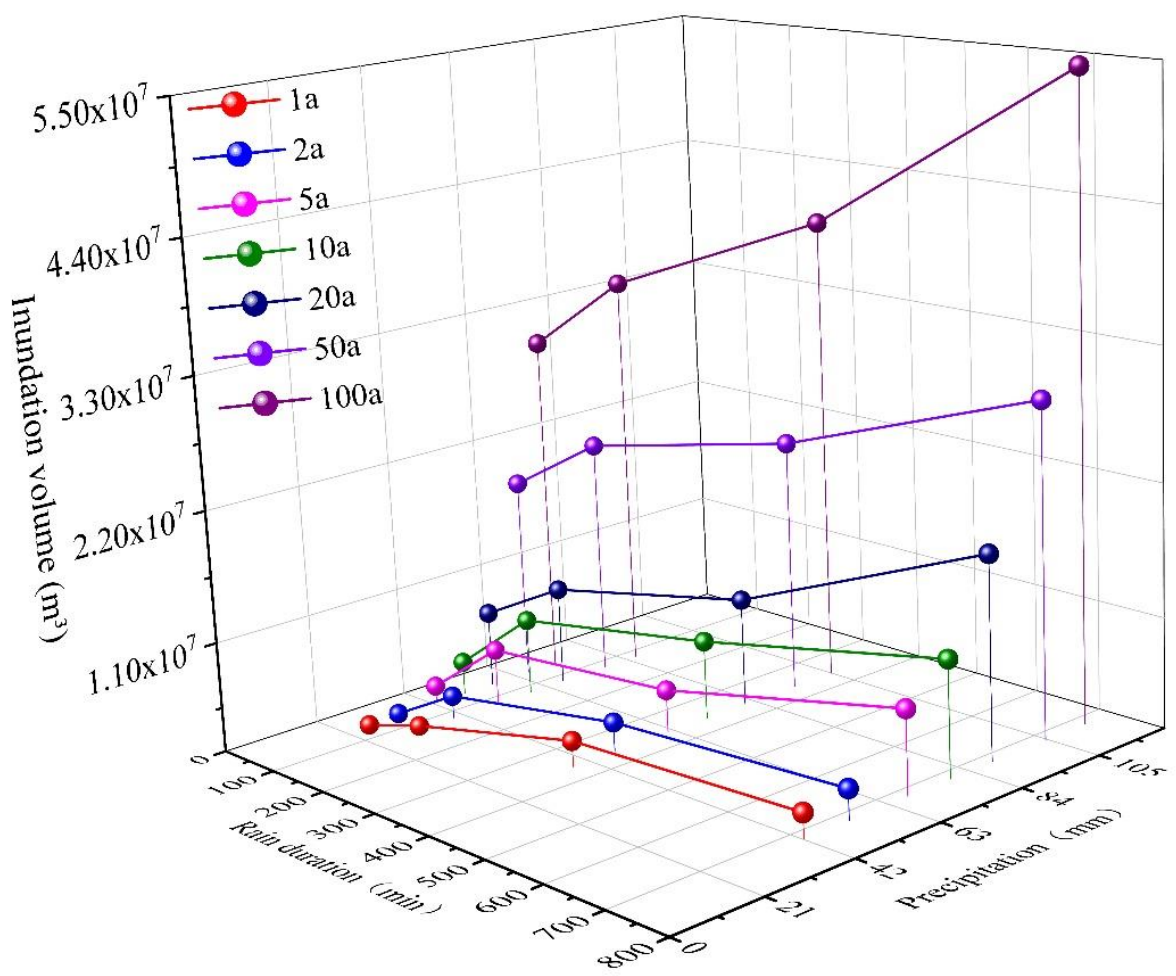

Figure 16. The relationship between submerged water volume and rainfall 


\subsection{Relationship between inundation volume and precipitation}

472

473

474

476

Based on the research results, we have compared and analyzed the correlation between rainfall and inundation (Fig.17) and quantitatively described. Rainfall and inundation show a good secondary correlation, $R^{2}$ is 0.8672 , which is helpful to the study of the relationship between urban waterlogging and rainfall threshold.

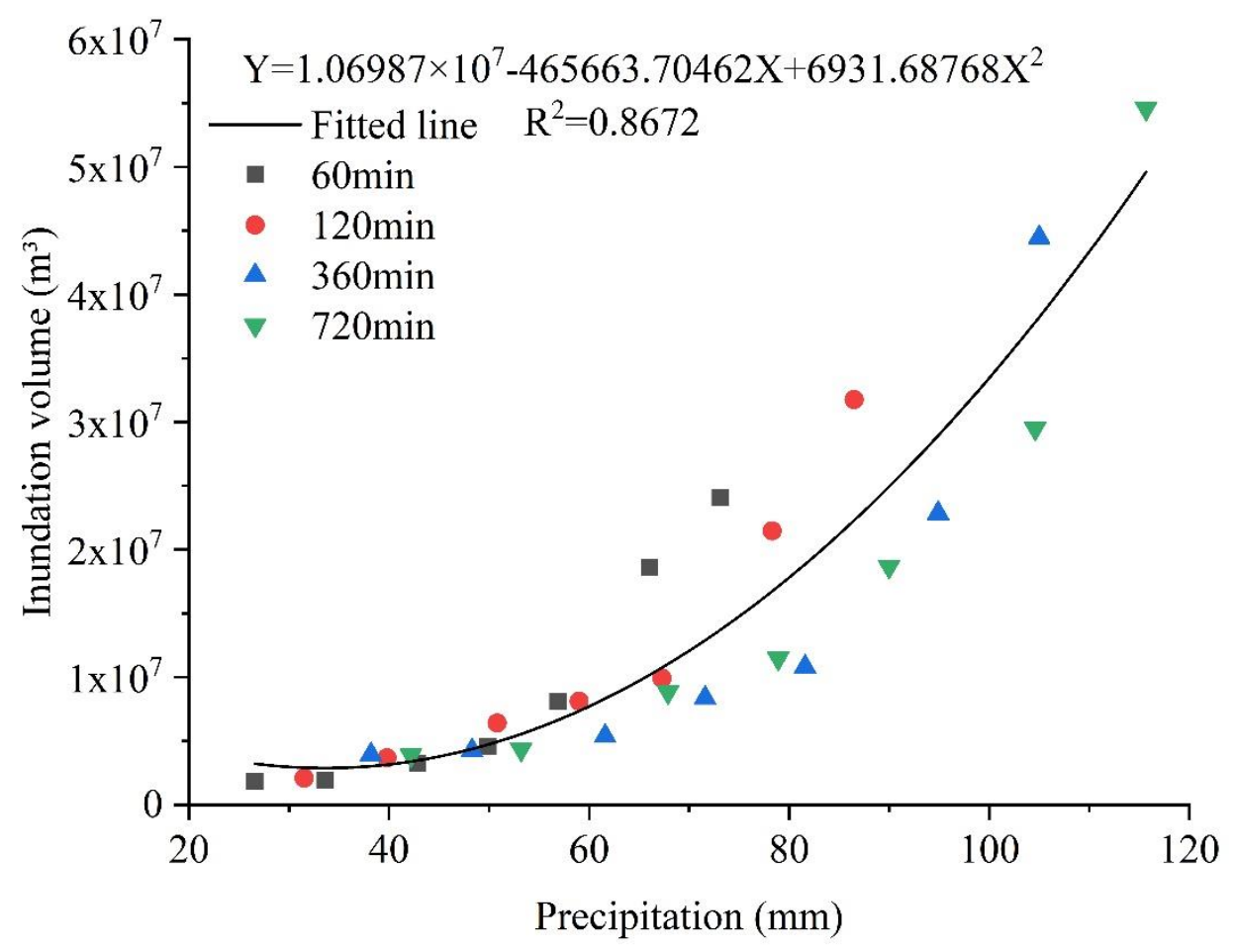

Figure 17. The relationship between submerged water volume and rainfall. In this study, the two factors of rainfall and rainfall duration have been studied on the impact of urban flooding and inundation. There are still many shortcomings. The uncertainty of rainfall input is the largest source of simulation errors in the urban rain flood model. Rainfall alone includes rainfall, rainfall duration, rain peak location, input events, rainfall sources and other internal factors. This study only discusses Rainfall and rainfall duration are two main factors. The influence of other factors on the urban 
rainwater model needs further study. Multi-source rainfall input is a research approach. In the current information explosion era, big data technology uses big data to effectively crawl network data as the rainfall model input; this is a topic of intense interest in current urban hydrological research. How to transform unstructured data into structured data and use dense data to drive urban rain and flood models will be a focus of future research $^{17}$.

\section{Conclusion}

This research puts forward the construction method of urban rain and flood model based on the complex underlying surface of the city, and explains the principle of urban waterlogging. Based on the one-dimensional-two-dimensional hydrodynamic method, the urban flood coupling model of surface overflow-pipe network overflow-river network overflow was successfully constructed and applied in examples. According to rainfall-inundation, we have systematically discussed the correlation between rainfall and rainfall duration on urban inundation. The main conclusions are as follows:

Based on the Mike series models, a coupled urban storm and flood model considering one-dimensional river channels, two-dimensional ground and underground pipe networks is constructed. Among them, Mike 11 is used to calculate the flood evolution and overflow inundation process of urban inland rivers; Mike Urban is used to build a simulated urban underground pipeline network flow calculation and rainwater well overflow inundation process; Mike 21 is used to simulate two-dimensional surface overflow of pipe networks and rivers Calculation. The above three models were coupled in Mike Flood, and the construction of a one-dimensional and two-dimensional coupled 
urban flood model and flood simulation were realized with the Luoyang city center as a pilot.

We selected the submerged water depths of 16 survey points in two historical storms and flood events to calibrate and verify the coupled model. The average relative error of simulated water depth during the calibration period was $22.65 \%$, the average absolute error was $13.93 \mathrm{~cm}$, and $R^{2}$ was 0.7835 ; The average relative error of the simulated water depth during the verification period is $15.27 \%$, the average absolute error is $7.54 \mathrm{~cm}$, and $R^{2}$ is 0.9548 . The simulation results are good.

We designed 28 rains with a return period of 1a, 2a, 5a, 10a, 20a, 50a, 100a, and a rainfall duration of $60 \mathrm{~min}, 120 \mathrm{~min}, 360 \mathrm{~min}, 720 \mathrm{~min}$, to simulate and analyze the rainstorm inundation in the downtown area of Luoyang. The calculation results: under the same return period, the shorter the rainfall duration, the faster the formation of inundation, the longer the rainfall duration, the longer the inundation duration; the greater the return period, the longer the rainfall duration, and the greater the maximum flooding water volume. Corresponding submerged time, submerged water depth, and maximum submerged water volume in dense building areas. the $R^{2}$ of rainfall and urban rainstorm inundation is 0.8776 , and the $R^{2}$ of rainfall duration and urban rainstorm inundation is 0.8141 . Therefore, the influencing factor that determines the magnitude of inundation is rainfall, followed by rainfall duration.

\section{References}

1. Grimm, N. B., Faeth, S. H., Golubiewski, N. E., Redman, C. L., Wu, J., Bai, X., \& Briggs, J. M. Global change and the ecology of cities. Science, 319(5864), 756-760 
2. Wang, J. Y., Hu, C. H., Ma, B. Y., \& Mu, X. L. Rapid Urbanization Impact on the (2017).

4. Jiang, X., \& Mostafavi, A. A network percolation-based contagion model of flood propagation and recession in urban road networks. Scientific Reports, 10(1) (2020).

5. Turner, A., Sahin, O., Giurco, D., Stewart, R., \& Porter, M. The potential role of desalination in managing flood risks from dam overflows: the case of Sydney, Australia. Journal of Cleaner Production, 135, 342-355 (2016).

6. Rahmati, O., Darabi, H., Panahi, M., Kalantari, Z., Naghibi, S. A., Santos Ferreira, C. S. Haghighi, A. T. Development of novel hybridized models for urban flood susceptibility mapping. Scientific Reports, 10(1) (2020).

7. Al-Zahrani, M. A. Assessing the impacts of rainfall intensity and urbanization on storm runoff in an arid catchment. Arabian Journal of Geosciences, 11(9) (2018).

8. Gao, Y., Yuan, Y., Wang, H., Zhang, Z., \& Ye, L. Analysis of impacts of polders on flood processes in Qinhuai River Basin, China, using the HEC-RAS model. Water Science and Technology-Water Supply, 18(5), 1852-1860 (2018).

9. Jiao, S., Zhang, X., \& Xu, Y. A review of Chinese land suitability assessment from the rainfall-waterlogging perspective: Evidence from the Su Yu Yuan area. Journal of Cleaner Production, 144, 100-106 (2017). 
10. Bach, P. M., Rauch, W., Mikkelsen, P. S., McCarthy, D. T., \& Deletic, A. A critical review of integrated urban water modelling Urban drainage and beyond. Environmental Modelling \& Software, 54, 88-107 (2014).

11. Chao Mei. Urban hydrology and hydrodynamic coupling model and its application research. (PhD), China Institute of Water Resources and Hydropower Research, Available from Cnki (2019).

12. Huang, G.-r., Wang, X., \& Huang, W. Simulation of Rainstorm Water Logging in Urban Area Based on InfoWorks ICM Model. Water Resources and Power, 35(2), 66-70, 60 (2017).

13. Van Der Knijff, J. M., Younis, J., \& De Roo, A. P. J. LISFLOOD: a GIS-based distributed model for river basin scale water balance and flood simulation. International Journal of Geographical Information Science, 24(2), 189-212 (2010).

14. Liu Jiahong, Xia Lin, Mei Chao, Shao Weiwei, Yu Haijun, Ma Jianming.Analysis of the role of deep tunnel drainage system in urban waterlogging prevention. Journal of Applied Basic Science and Engineering, 27(02):252-263 (2019).

15. Guoru Huang, Haiwan Luo, Wenjie Chen, \& Jian Pan. Urban flood disaster scenario simulation and risk assessment in Donghaoyong River Basin, Guangzhou. Advances in Water Science, 0(05), 643-652 (2019).

16. Zischg, A. P., Mosimann, M., Bernet, D. B., \& Rothlisberger, V. Validation of 2D flood models with insurance claims. Journal of Hydrology, 557, 350-361 (2018).

17. Lowe, R., Urich, C., Domingo, N. S., Mark, O., Deletic, A., \& Arnbjerg-Nielsen, K. Assessment of urban pluvial flood risk and efficiency of adaptation options through 
simulations - A new generation of urban planning tools. Journal of Hydrology, 550, 355-367 (2017).

18. Martins, R., Leandro, J., \& Djordjevic, S. Influence of sewer network models on Risk Management, 11, S717-S728 (2018).

19. Fraga, I., Cea, L., \& Puertas, J. Validation of a 1D-2D dual drainage model under unsteady part-full and surcharged sewer conditions. Urban Water Journal, 14(1), 7484 (2017).

20. Leandro, J., Schumann, A., \& Pfister, A. A step towards considering the spatial heterogeneity of urban key features in urban hydrology flood modelling. Journal of Hydrology, 2016,535, 356-365 (2017).

21. van der Sterren, M., Rahman, A., \& Ryan, G. Modeling of a lot scale rainwater tank system in XP-SWMM: A case study in Western Sydney, Australia. Journal of Environmental Management, 141, 177-189 (2014).

22. Gong, Y., Li, X., Zhai, D., Yin, D., Song, R., Li, J., . . Yuan, D. Influence of Rainfall, Model Parameters and Routing Methods on Stormwater Modelling. Water Resources Management, 32(2), 735-750 (2018).

23. Cheng, M., Qin, H., Fu, G., \& He, K. Performance evaluation of time-sharing utilization of multi-function sponge space to reduce waterlogging in a highly urbanizing area. Journal of Environmental Management, 269 (2020).

24. Bruni, G., Reinoso, R., van de Giesen, N. C., Clemens, F. H. L. R., \& ten Veldhuis, J. A. E. On the sensitivity of urban hydrodynamic modelling to rainfall spatial and 
temporal resolution. Hydrology and Earth System Sciences, 19(2), 691-709 (2015).

25. Bermudez, M., Ntegeka, V., Wolfs, V., \& Willens, P. Development and Comparison of Two Fast Surrogate Models for Urban Pluvial Flood Simulations. Water Resources Management, 32(8), 2801-2815 (2018).

26. Indrawati, D., Yakti, B., Purwanti, A., \& Hadinagoro, R. Computing urban flooding of meandering river using 2D numerical model (case study : Kebon Jati-Kalibata segment, Ciliwung river basin). In R. D. Wirahadikusumah, B. Hasiholan, \& P. Kusumaningrum (Eds.), 2nd Conference for Civil Engineering Research Networks (Vol. 270), (2019).

27. Yu, D., Yin, J., \& Liu, M. Validating city-scale surface water flood modelling using crowd-sourced data. Environmental Research Letters, 11(12) (2016).

28. Chen, W. J., Huang, G. R., Zhang, H., \& Wang, W. Q. Urban inundation response to rainstorm patterns with a coupled hydrodynamic model: A case study in Haidian Island, China. Journal of Hydrology, 564, 1022-1035 (2018).

29. Jang, J.-H. An Advanced Method to Apply Multiple Rainfall Thresholds for Urban Flood Warnings. Water, 7(11), 6056-6078 (2015).

30. Wu, X., Wang, Z., Guo, S., Liao, W., Zeng, Z., \& Chen, X. Scenario-based projections of future urban inundation within a coupled hydrodynamic model framework: A case study in Dongguan City, China. Journal of Hydrology, 547, 428442 (2017).

31. de Souza, B. A., Paz, I. d. S. R., Ichiba, A., Willinger, B., Gires, A., Amorim, J. C. C., Schertzer, D. Multi-hydro hydrological modelling of a complex peri-urban 
catchment with storage basins comparing C-band and X-band radar rainfall data. Hydrological Sciences Journal-Journal Des Sciences Hydrologiques, 63(11), 16191635 (2018).

32. Kim, S. E., Lee, S., Kim, D., \& Song, C. G. Stormwater Inundation Analysis in Small and Medium Cities for the Climate Change Using EPA-SWMM and HDM2D. Journal of Coastal Research, 991-995 (2018).

33. Wang, J., Forman, B. A., \& Davis, A. P. Probabilistic Stormwater Runoff and Water Quality Modeling of a Highway in Suburban Maryland. Journal of Hydrologic

34. Hu, C. H., Zhang, L., Wu, Q., Soomro, S. E. H., \& Jian, S. Q. Response of LUCC on Runoff Generation Process in Middle Yellow River Basin: The Gushanchuan Basin. Water, 12(5) (2020).

35. Hu, C. H., Liu, C. S., Yao, Y. C., Wu, Q., Ma, B. Y., \& Jian, S. Q. Evaluation of the Impact of Rainfall Inputs on Urban Rainfall Models: A Systematic Review. Water, 12(9) (2020).

36. Nash, J.E., Sutcliffe, J.V. River flow forecasting through conceptual models part I - a discussion of principles. Journal of Hydrology, 10(3): 0-290 (1970).

37. Li, F., Liu, H., Huisingh, D., Wang, Y., \& Wang, R. Shifting to healthier cities with improved urban ecological infrastructure: From the perspectives of planning, implementation, governance and engineering. Journal of Cleaner Production, 163, S1-S11 (2017).

38. Djordjevic, S., Prodanovic, D., Maksimovic, C., Ivetic, M., \& Savic, D. SIPSON - 
Simulation of interaction between pipe flow and surface overland flow in networks. Water Science and Technology, 52(5), 275-283 (2005).

39. Jamali, B., Lowe, R., Bach, P. M., Urich, C., Arnbjerg-Nielsen, K., \& Deletic, A. A rapid urban flood inundation and damage assessment model. Journal of Hydrology, 564, 1085-1098 (2018).

\section{Authors Contributions}

For this research paper with several authors, a short paragraph specifying their individual contributions was provided. Chengshuai Liu developed the original idea and contributed to the research design for the study. Fang Yang was responsible for data collecting. Caihong $\mathrm{Hu}$, and Bin Zha provided guidance and improving suggestion. Yichen Yao, and Yue Sun provided some guidance for the writing of the article. All authors have read and approved the final manuscript.

\section{Funding}

This work was funded by Key projects of National Natural Science Foundation of China, grant number 51739009, National Natural Science Foundation of China, grant number 51979250 .

\section{Declaration of competing interest}

The authors declare that there is no conflict of interest regarding the publication of this paper.

\section{Availability of data and material}

Not applicable. The data in this manuscript is also used in other ongoing research, 
660 so data and materials are not applicable. 


\section{Figures}

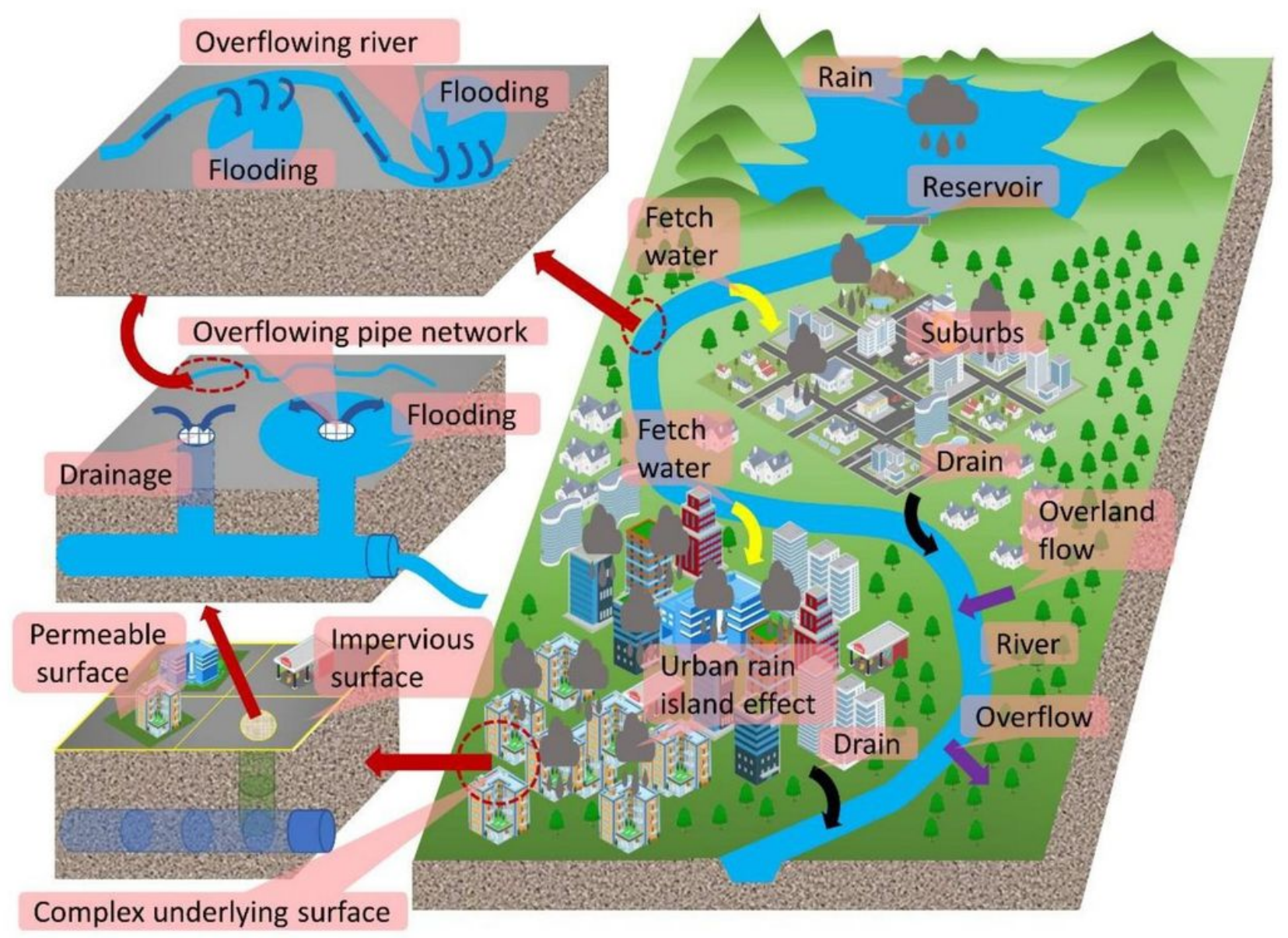

\section{Figure 1}

Schematic diagram of urban rain flood inundation principle. (Compared with natural watersheds, the underlying surface conditions of cities are more complicated. Urban floods also include three parts: pipe network overflow, river overflow, and surface overflow.) Note: The designations employed and the presentation of the material on this map do not imply the expression of any opinion whatsoever on the part of Research Square concerning the legal status of any country, territory, city or area or of its authorities, or concerning the delimitation of its frontiers or boundaries. This map has been provided by the authors. 


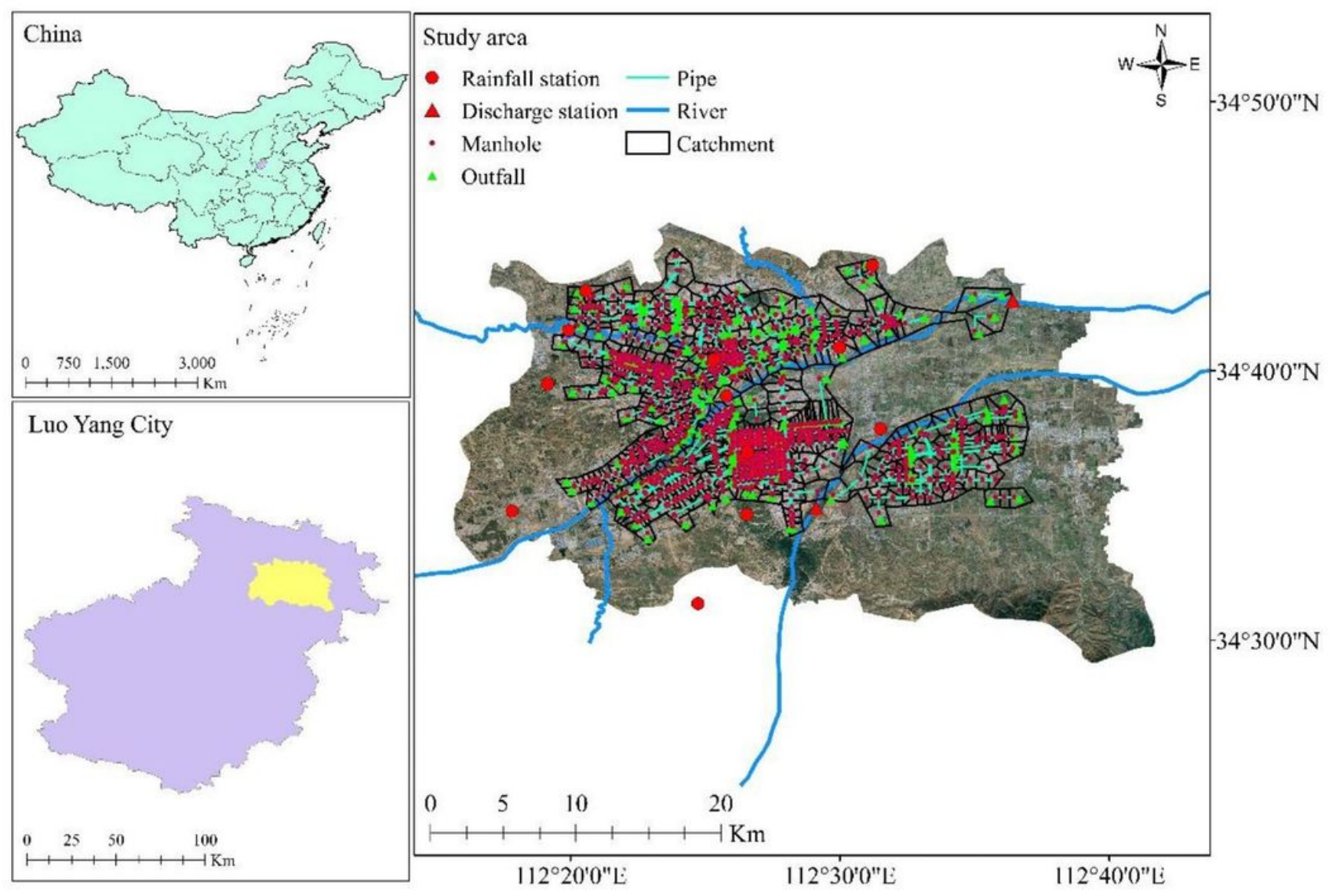

Figure 2

Research region and sewer system distribution. We selected Luoyang city center, in the northern Henan Province of China, as our study area $\left(34^{\circ} 29^{\prime} 06^{\prime \prime}-34^{\circ} 45^{\prime} 47^{\prime \prime} \mathrm{N}, 112^{\circ} 15^{\prime} 44^{\prime \prime}-112^{\circ} 41^{\prime} 57^{\prime \prime} \mathrm{E}\right.$, at $150 \mathrm{~m}$ asl) (Fig. 1). Luoyang city center, which constitutes the northern part of Luoyang city, is a typical small basin city with an area of $803 \mathrm{~km} 2$, and is situated within the Yi-Luo River Basin. The two rivers of Yi he and Luo he passed through the downtown area of Luoyang. Note: The designations employed and the presentation of the material on this map do not imply the expression of any opinion whatsoever on the part of Research Square concerning the legal status of any country, territory, city or area or of its authorities, or concerning the delimitation of its frontiers or boundaries. This map has been provided by the authors. 


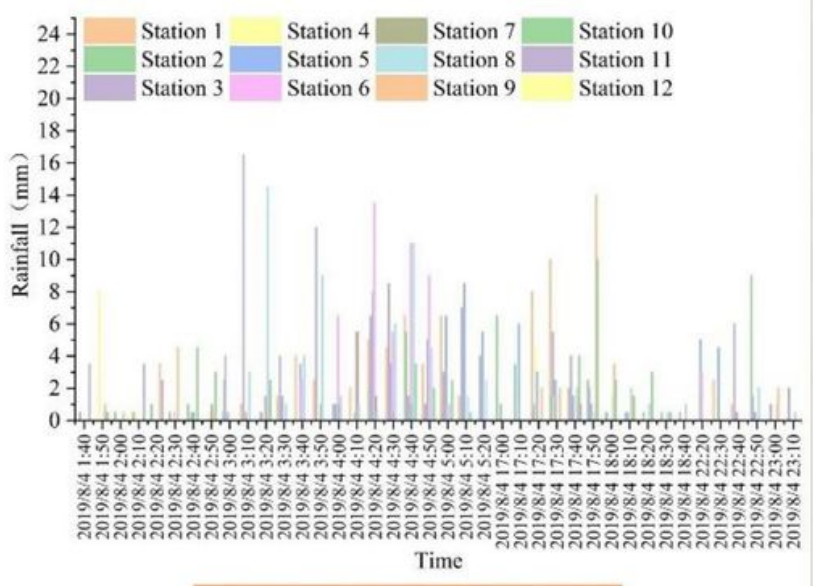

Storm 1: 20190804

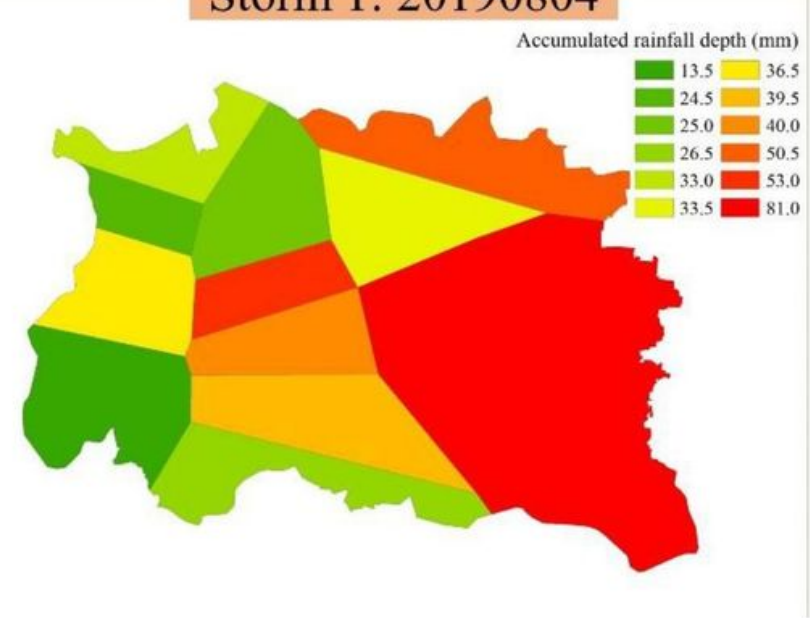

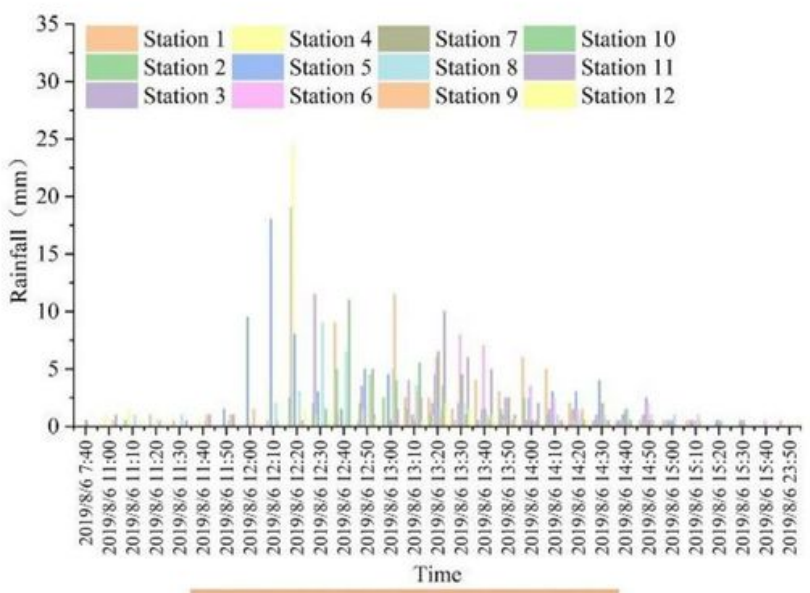

Storm 2: 20190806

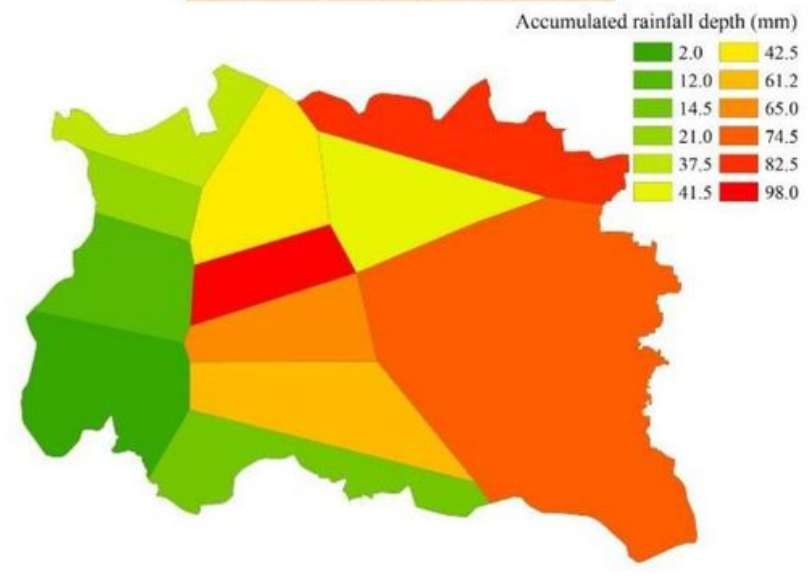

\section{Figure 3}

Hydrographs of the two historical rainstorms (August 4, 2019 and August 6, 2019). Storm 1 started at 1:40 and ended at 23:10 on August 4, 2019. It is a unimodal rainstorm, the first rainfall peak occurred at $3: 10$ with an intensity of $16.5 \mathrm{~mm} / \mathrm{h}$ and the second rainfall peak occurred at 17:30 with an intensity of $5.5 \mathrm{~mm} / \mathrm{h}$. Storm 2 started at 7:40 and ended at 23:50 lasted about 22h on August 6, 2019 with the maximum intensity of $24.0 \mathrm{~mm} / \mathrm{h}$ occurred at 12:20. Fig. 3 shows the hydrographs of the storms. Note: The designations employed and the presentation of the material on this map do not imply the expression of any opinion whatsoever on the part of Research Square concerning the legal status of any country, territory, city or area or of its authorities, or concerning the delimitation of its frontiers or boundaries. This map has been provided by the authors. 

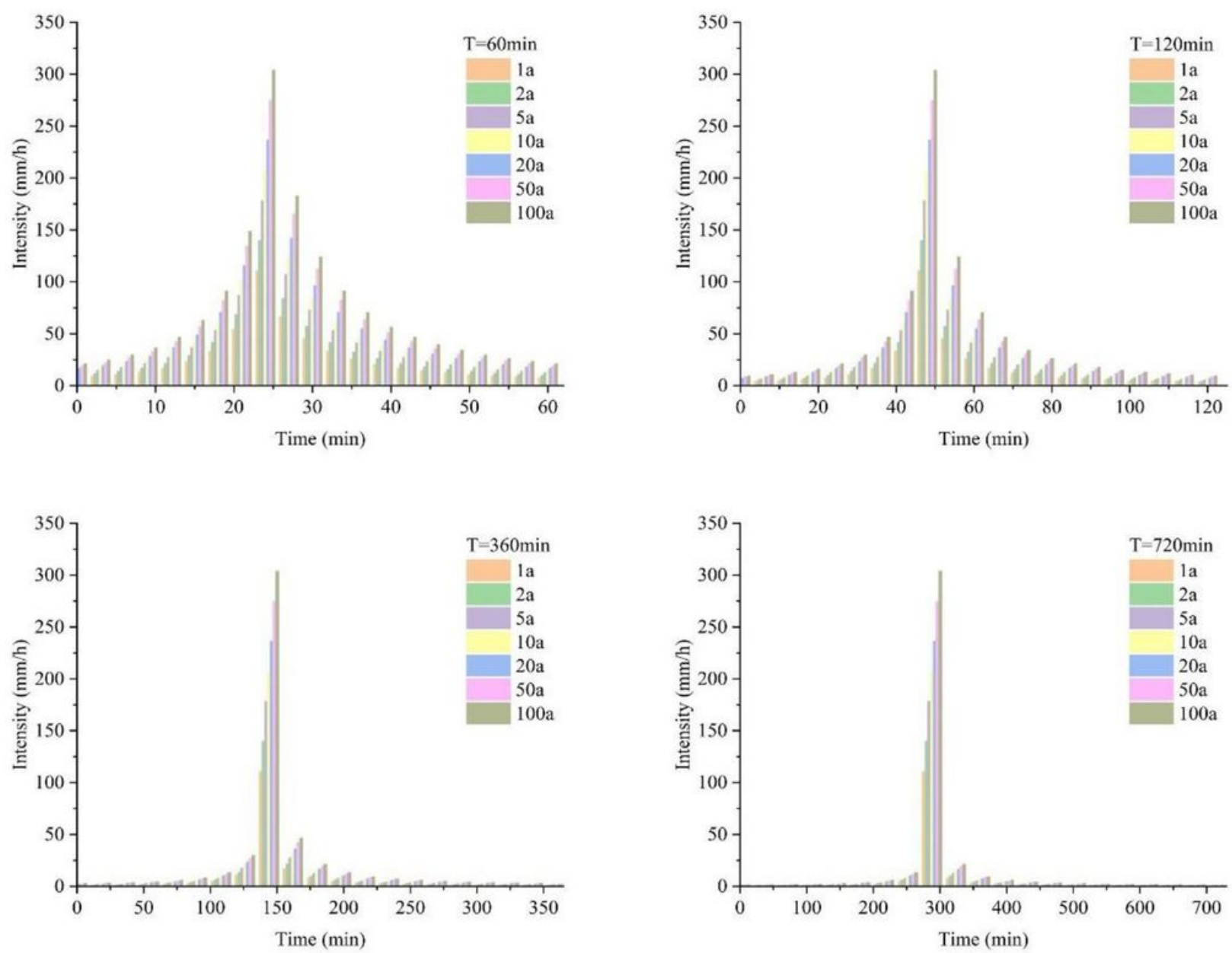

\section{Figure 4}

Synthetic hyetograph of four rainstorm patterns. The main difference among the four rainstorm patterns is the position of the rainfall duration, the rainfall duration were set to $60 \mathrm{~min}, 120 \mathrm{~min}, 360 \mathrm{~min}$, and 720min (Fig.4). We named these four rainstorms (Fig.4) as Pattern 1, Pattern 2, Pattern 3, and Pattern 4. 


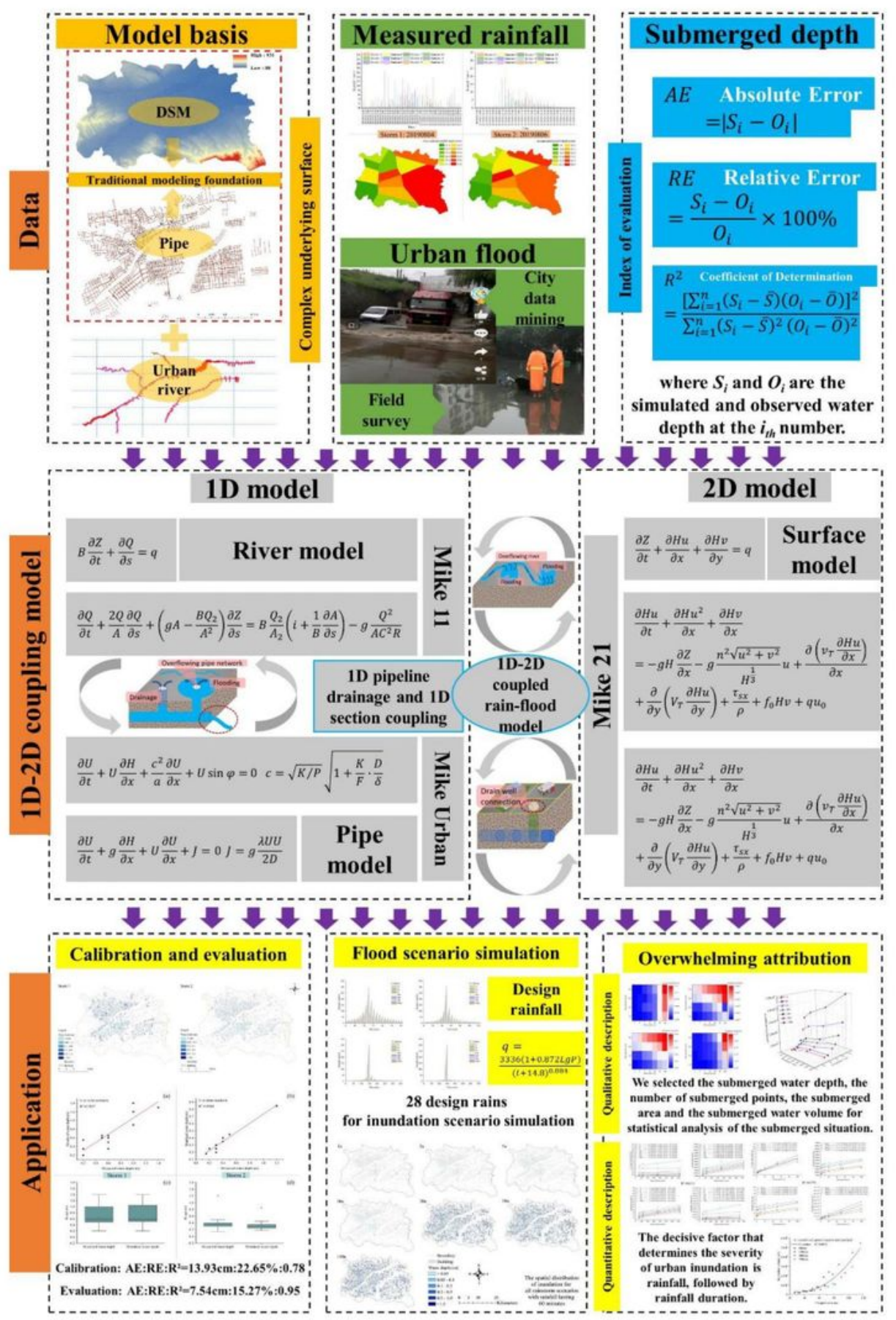

\section{Figure 5}

1D-2D rainfall flood model coupling scheme (The process frame diagram of this study) Note: The designations employed and the presentation of the material on this map do not imply the expression of any opinion whatsoever on the part of Research Square concerning the legal status of any country, territory, city or area or of its authorities, or concerning the delimitation of its frontiers or boundaries. This map has been provided by the authors. 

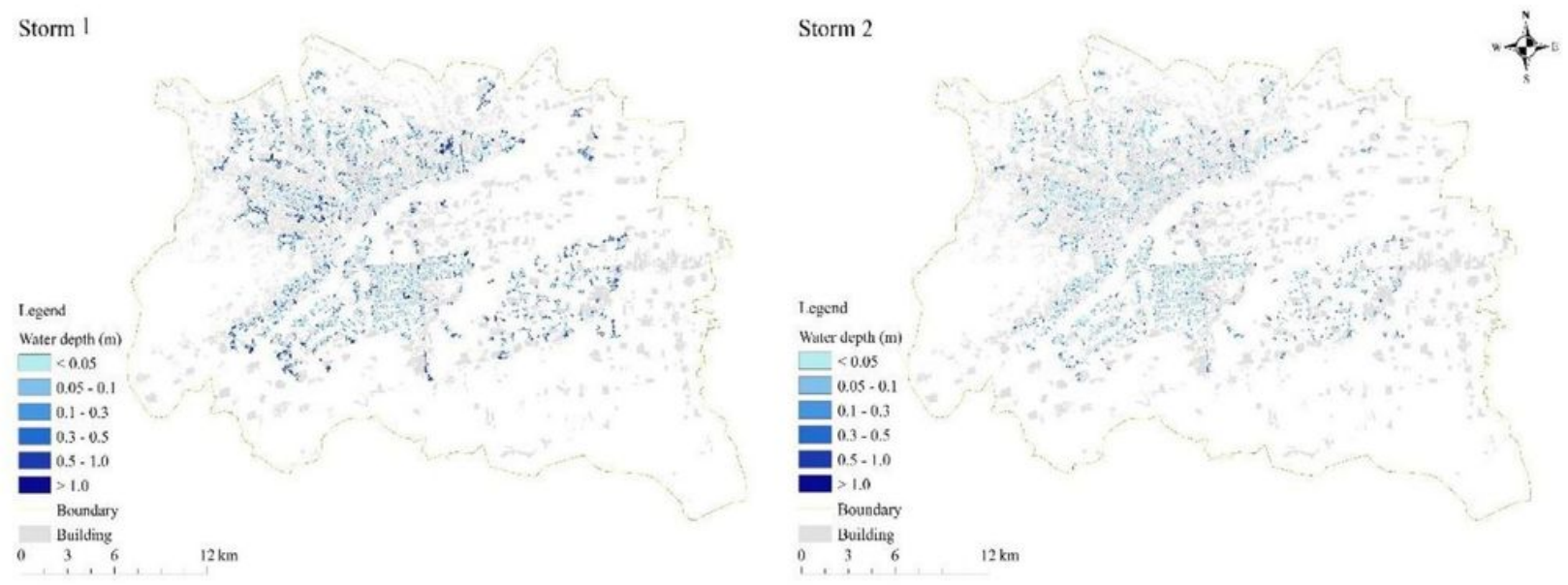

\section{Figure 6}

Spatial distributions of inundations from Storm 1 and Storm 2. Note: The designations employed and the presentation of the material on this map do not imply the expression of any opinion whatsoever on the part of Research Square concerning the legal status of any country, territory, city or area or of its authorities, or concerning the delimitation of its frontiers or boundaries. This map has been provided by the authors. 


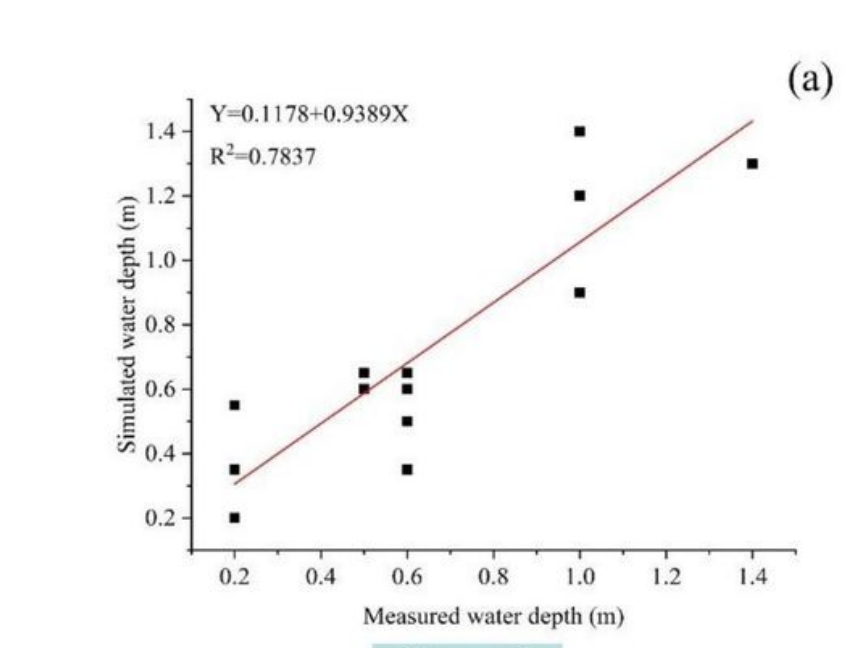

Storm 1

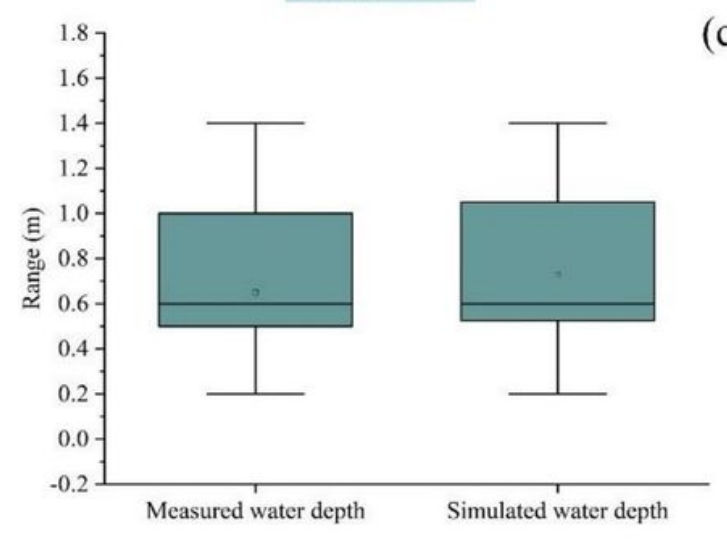

(b)

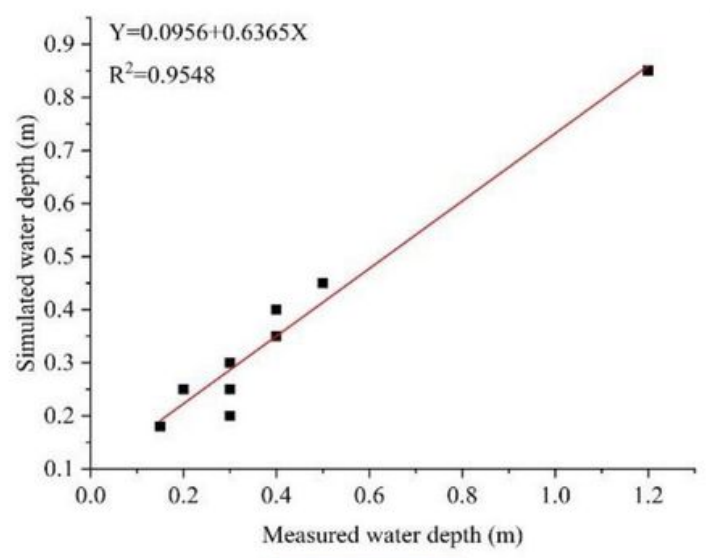

Storm 2

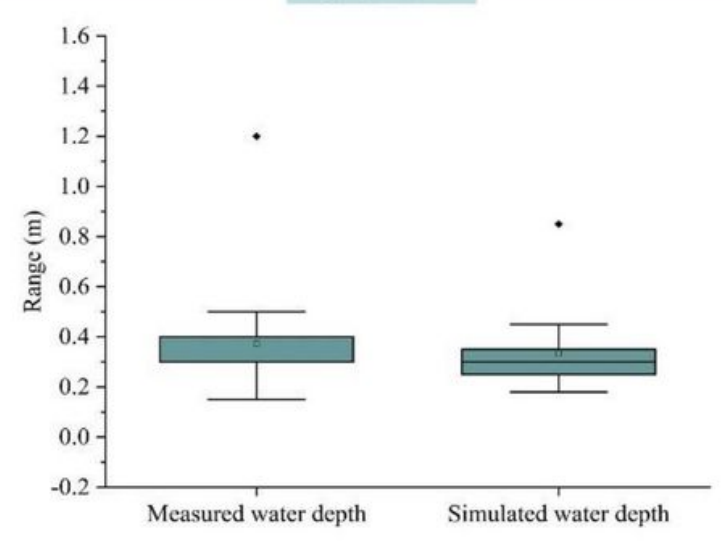

\section{Figure 7}

Comparison of simulated water depth and measured water depth of Storm 1 and Storm 2. 

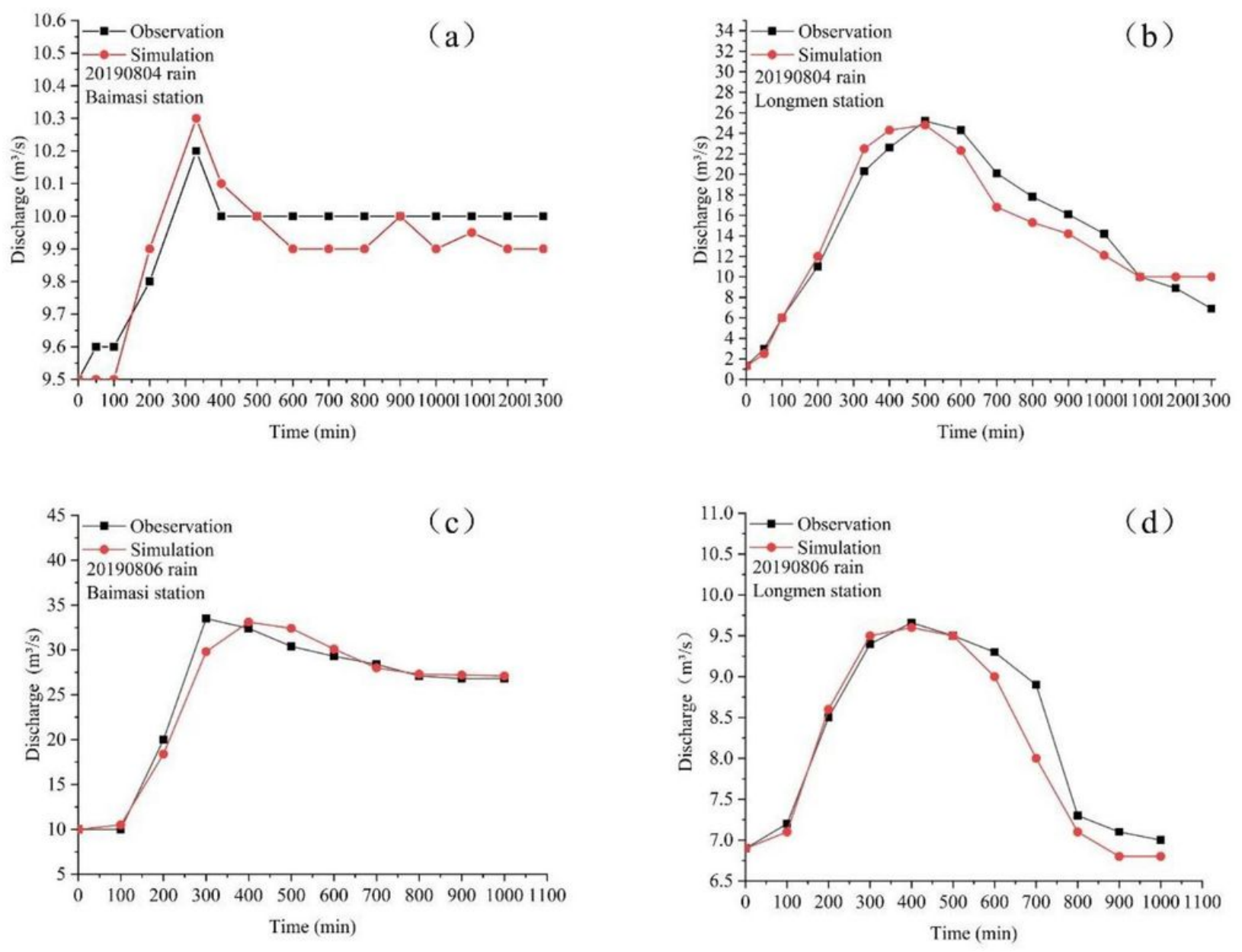

Figure 8

Comparison of simulated discharge and observed discharge of Storm 1 and Storm 2: (a) Discharge calibration of 20190804 rain in Baimasi station; (b) Discharge calibration of 20190804 rain in Longmen station; (c) Discharge evaluation of 20190806 rain in Baimasi station; (d) Discharge evaluation of 20190806 rain in Longmen station 

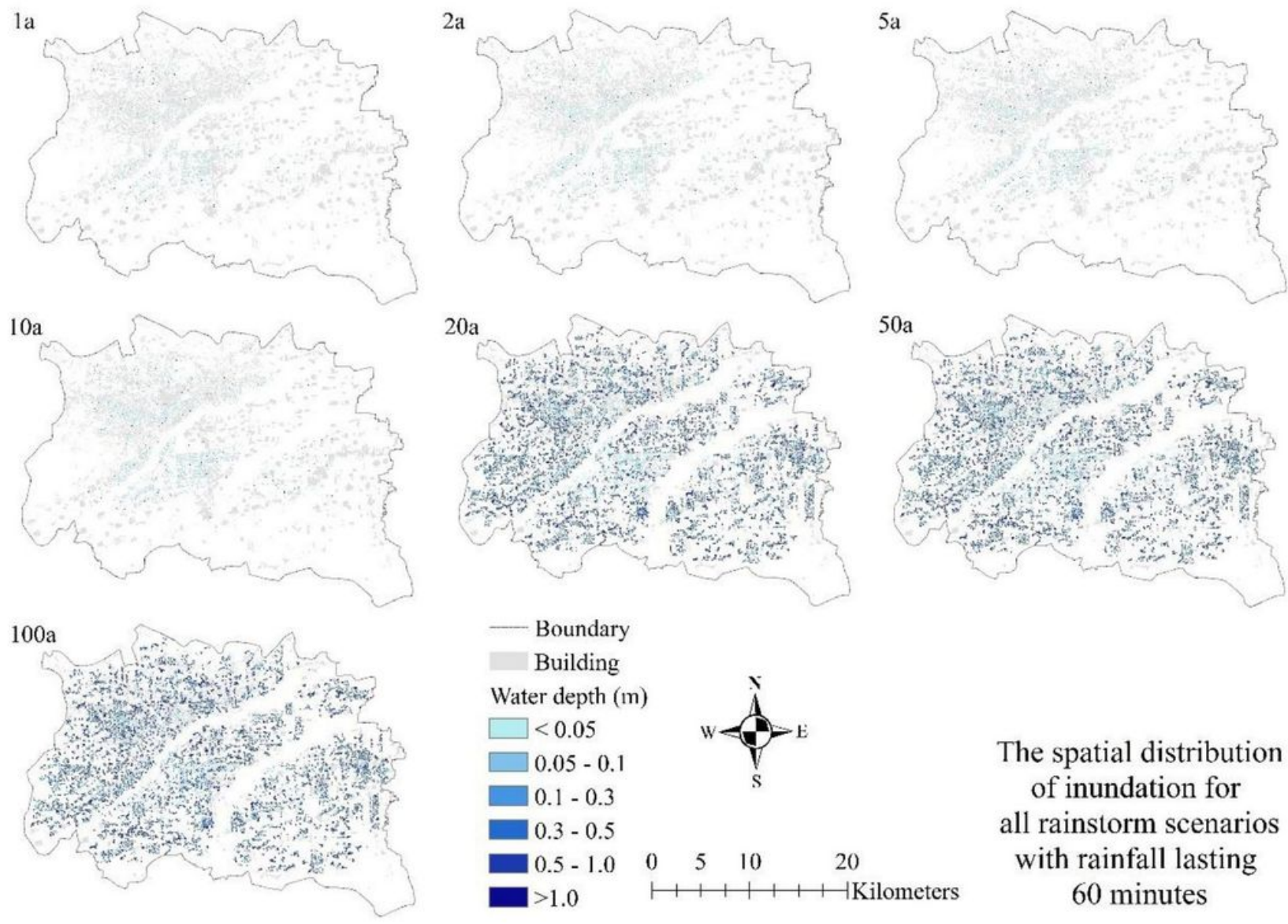
The spatial distribution of inundation for all rainstorm scenarios with rainfall lasting 60 minutes

\section{Figure 9}

Spatial distributions of inundation for $60 \mathrm{~min}$ rainstorm scenarios. Note: The designations employed and the presentation of the material on this map do not imply the expression of any opinion whatsoever on the part of Research Square concerning the legal status of any country, territory, city or area or of its authorities, or concerning the delimitation of its frontiers or boundaries. This map has been provided by the authors. 

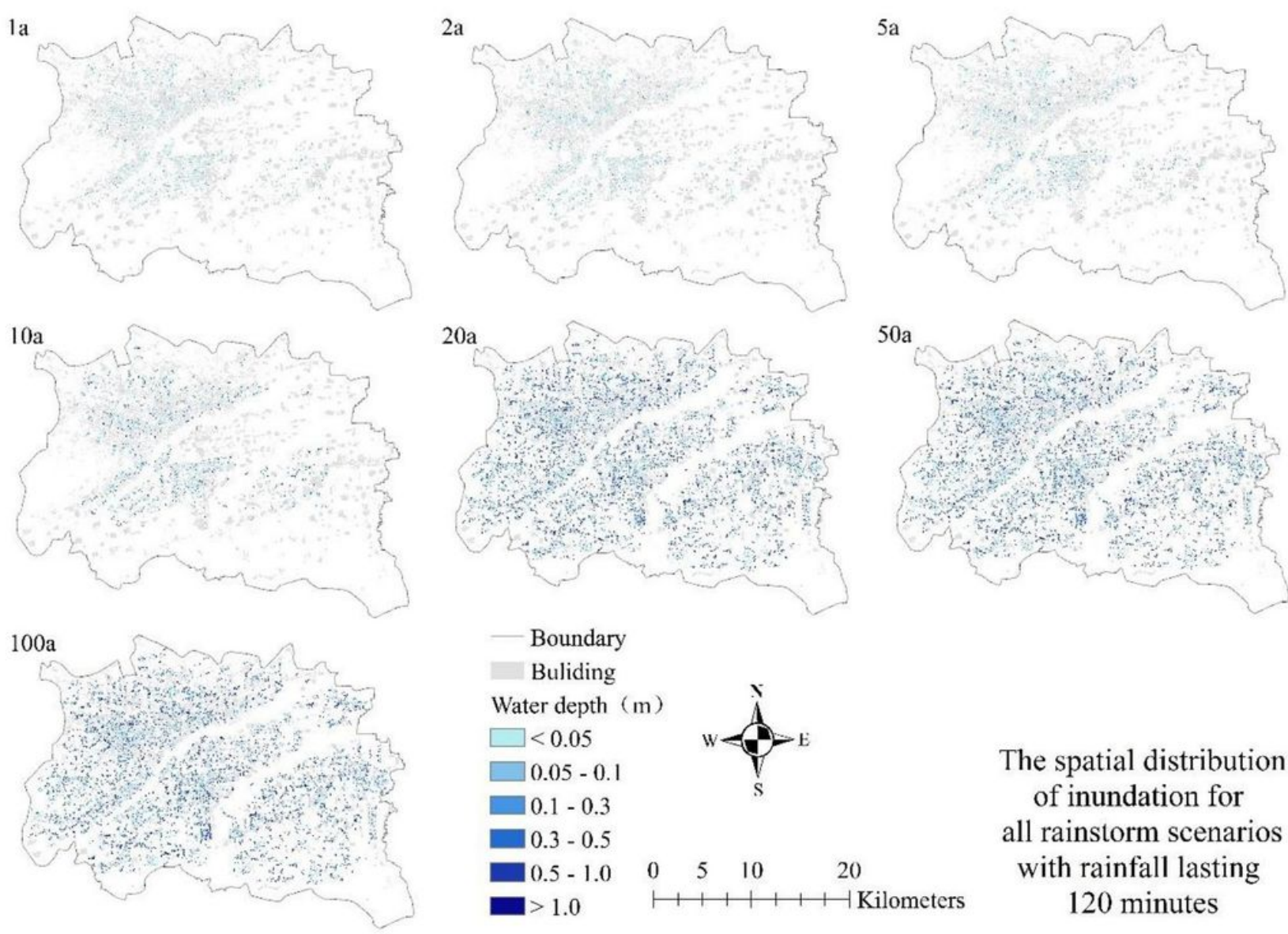
The spatial distribution of inundation for all rainstorm scenarios with rainfall lasting 120 minutes

\section{Figure 10}

Spatial distributions of inundation for $120 \mathrm{~min}$ rainstorm scenarios. Note: The designations employed and the presentation of the material on this map do not imply the expression of any opinion whatsoever on the part of Research Square concerning the legal status of any country, territory, city or area or of its authorities, or concerning the delimitation of its frontiers or boundaries. This map has been provided by the authors. 

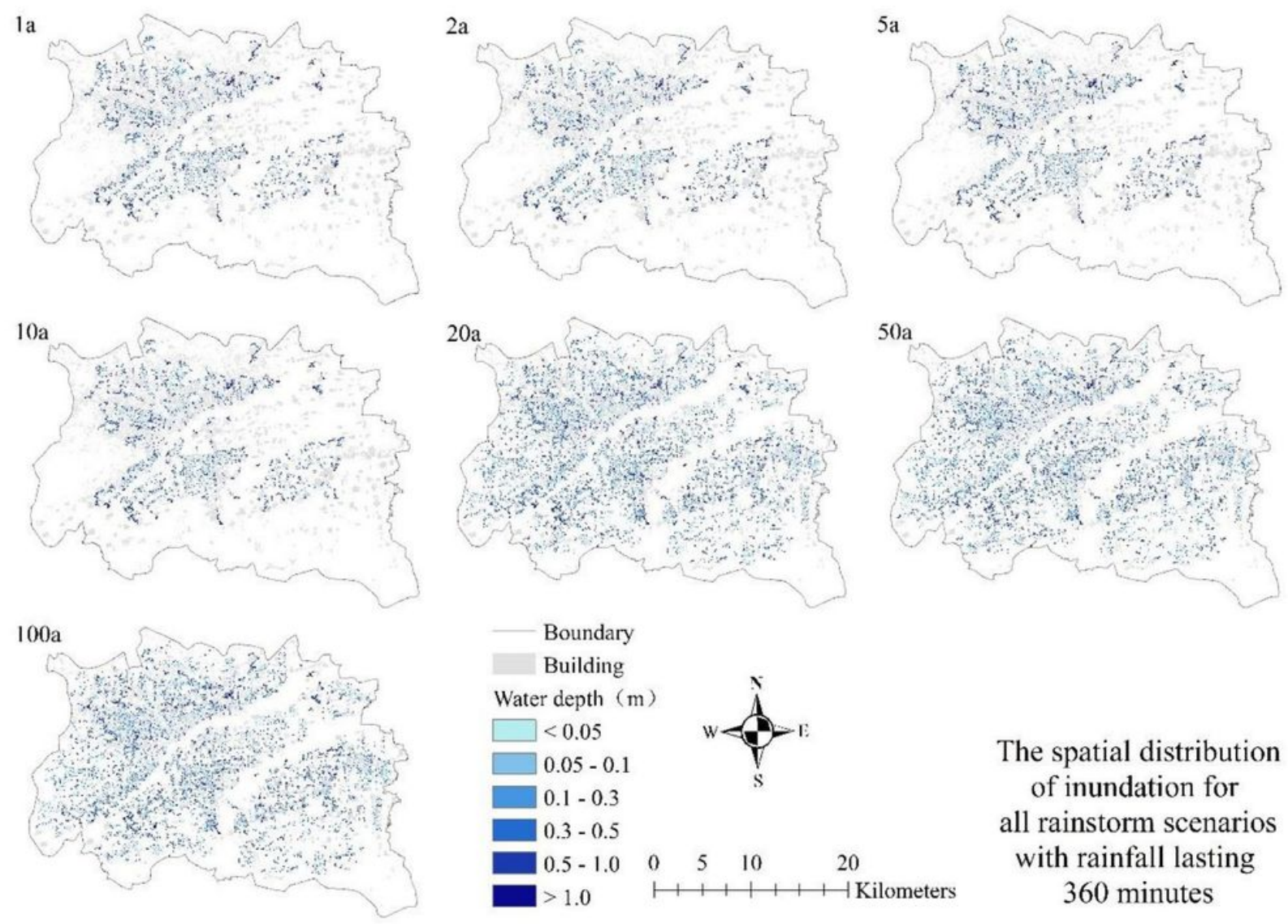

The spatial distribution of inundation for all rainstorm scenarios with rainfall lasting 360 minutes

\section{Figure 11}

Spatial distributions of inundation for 360min rainstorm scenarios. Note: The designations employed and the presentation of the material on this map do not imply the expression of any opinion whatsoever on the part of Research Square concerning the legal status of any country, territory, city or area or of its authorities, or concerning the delimitation of its frontiers or boundaries. This map has been provided by the authors. 

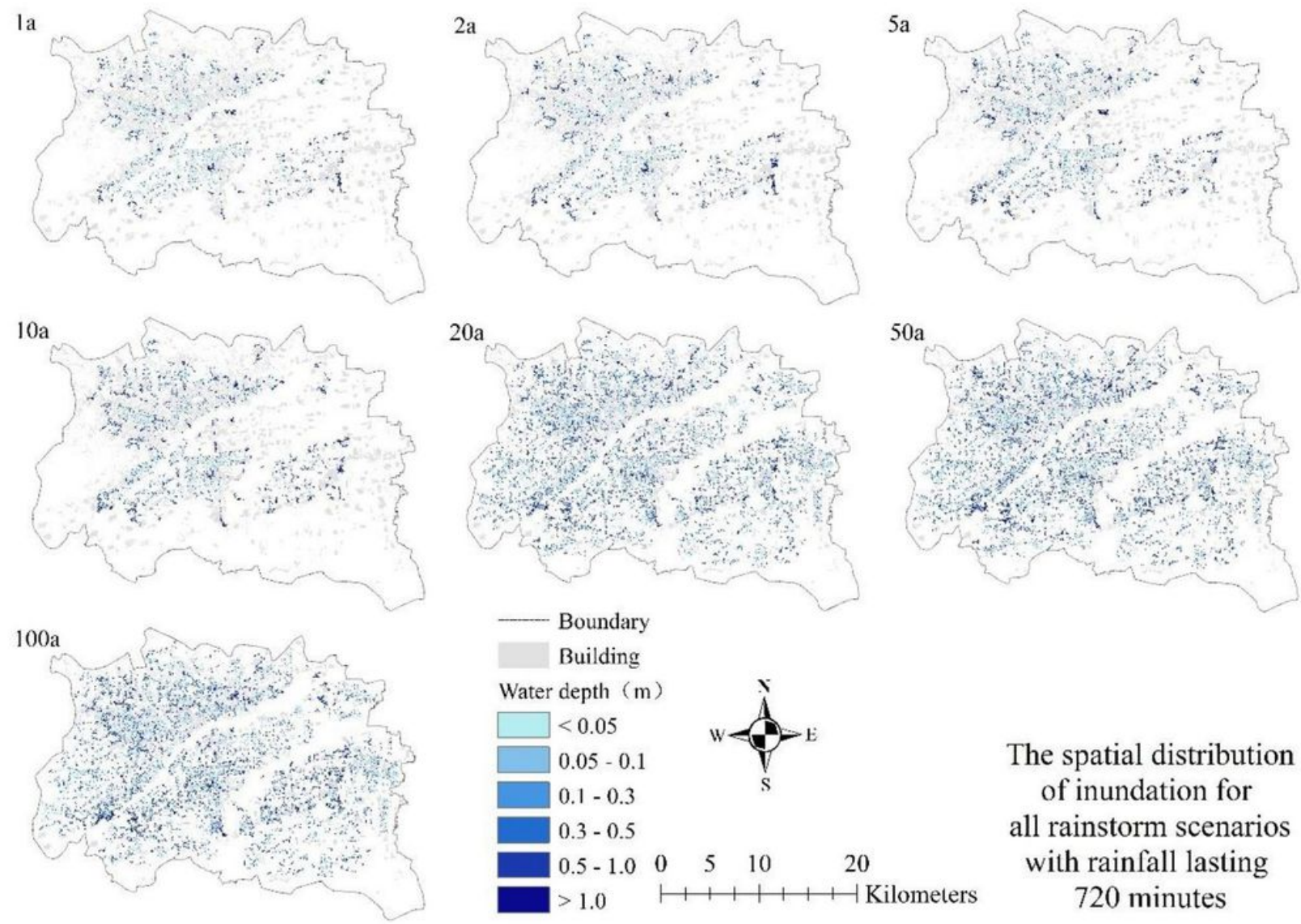
The spatial distribution of inundation for all rainstorm scenarios with rainfall lasting
720 minutes

\section{Figure 12}

Spatial distributions of inundation for $720 \mathrm{~min}$ rainstorm scenarios. Note: The designations employed and the presentation of the material on this map do not imply the expression of any opinion whatsoever on the part of Research Square concerning the legal status of any country, territory, city or area or of its authorities, or concerning the delimitation of its frontiers or boundaries. This map has been provided by the authors. 

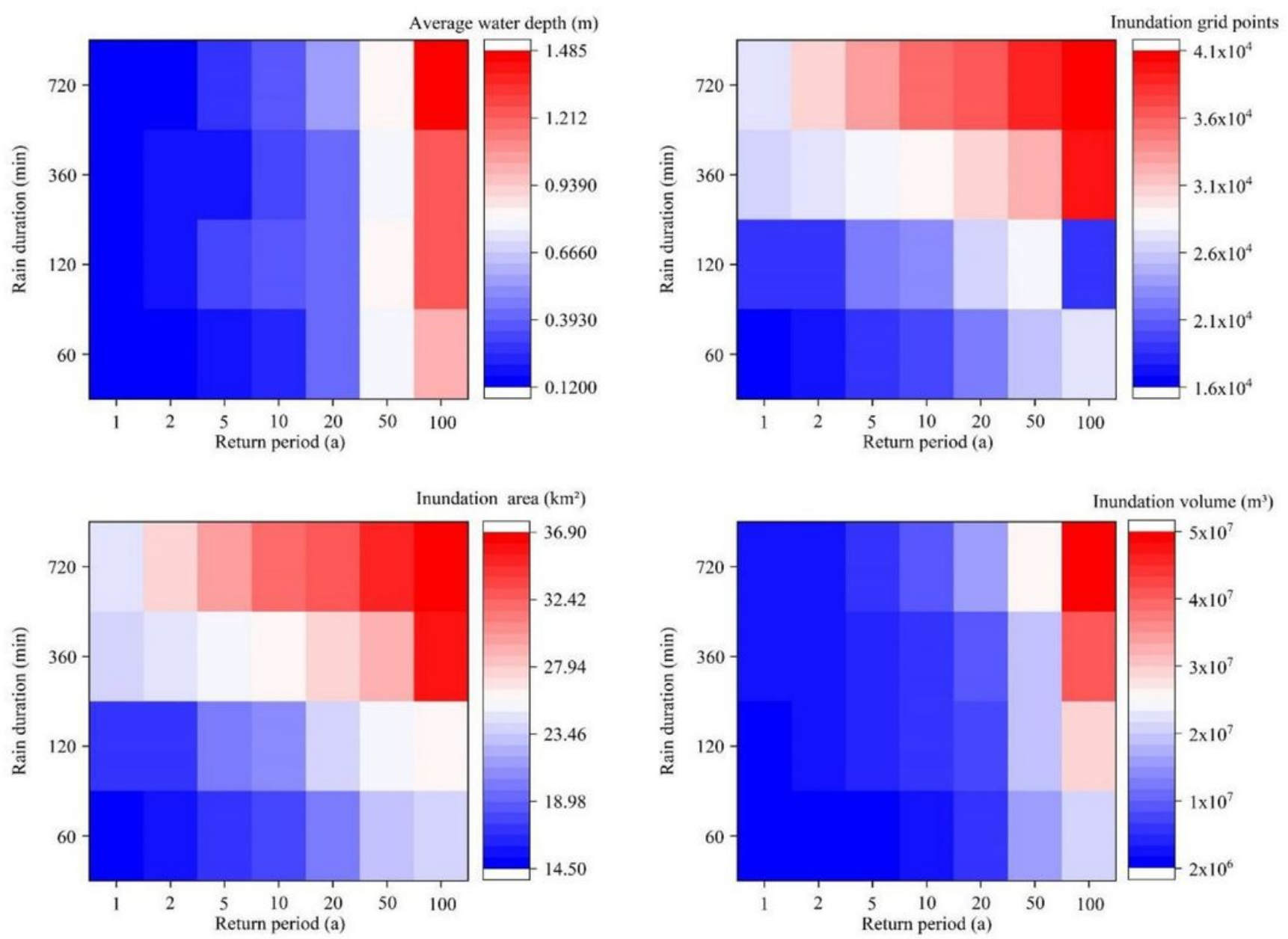

Figure 13

(a)The relationship between the average submerged water depth and the return period and duration of rainfall. (b)The relationship between the number of submerged grid points and the rainfall return period and rainfall duration. (c)The relationship between submerged area and rainfall return period and rainfall duration. (d)The relationship between submerged water volume and rainfall return period and rainfall duration. 


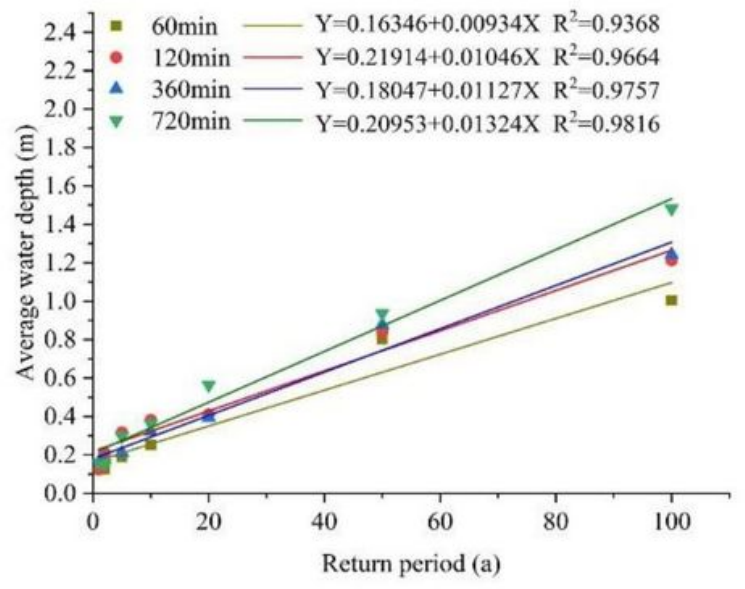

\section{$\mathrm{R}^{2}=0.8776$}

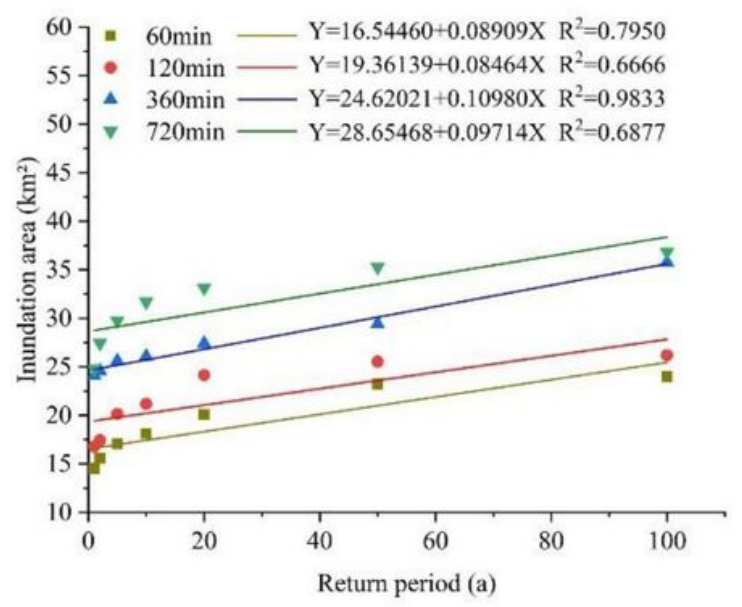

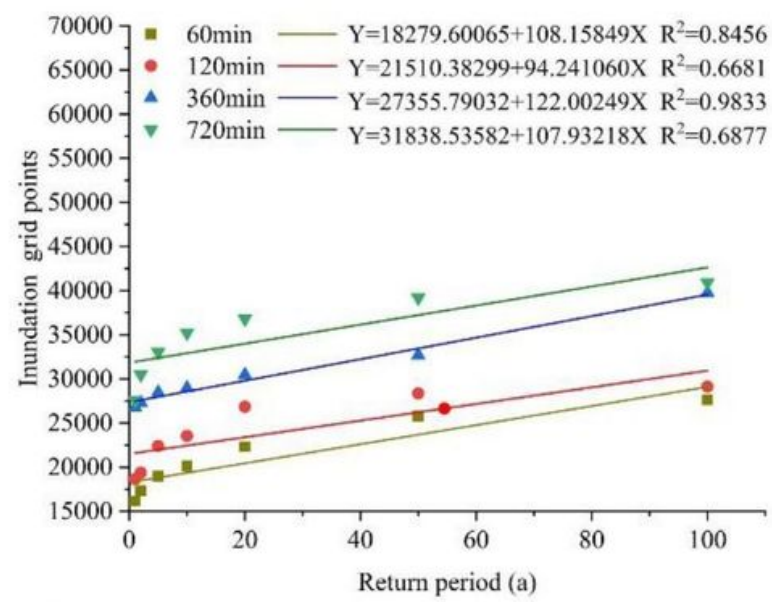

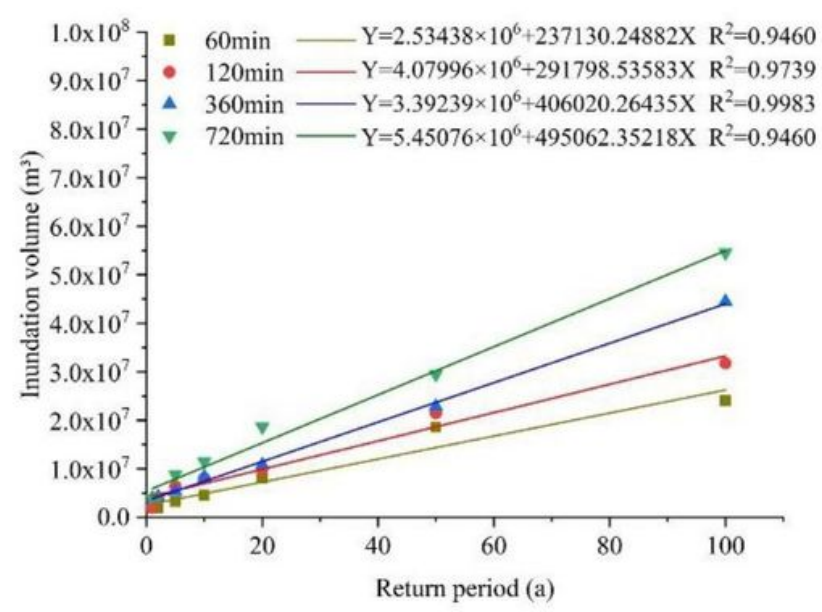

\section{Figure 14}

Trend chart of relationship between submerged water depth, submerged grid points, submerged area, submerged water volume and return period. (The return period and the four submergence indicators are linearly correlated, with an average R2 of 0.8776 .) 

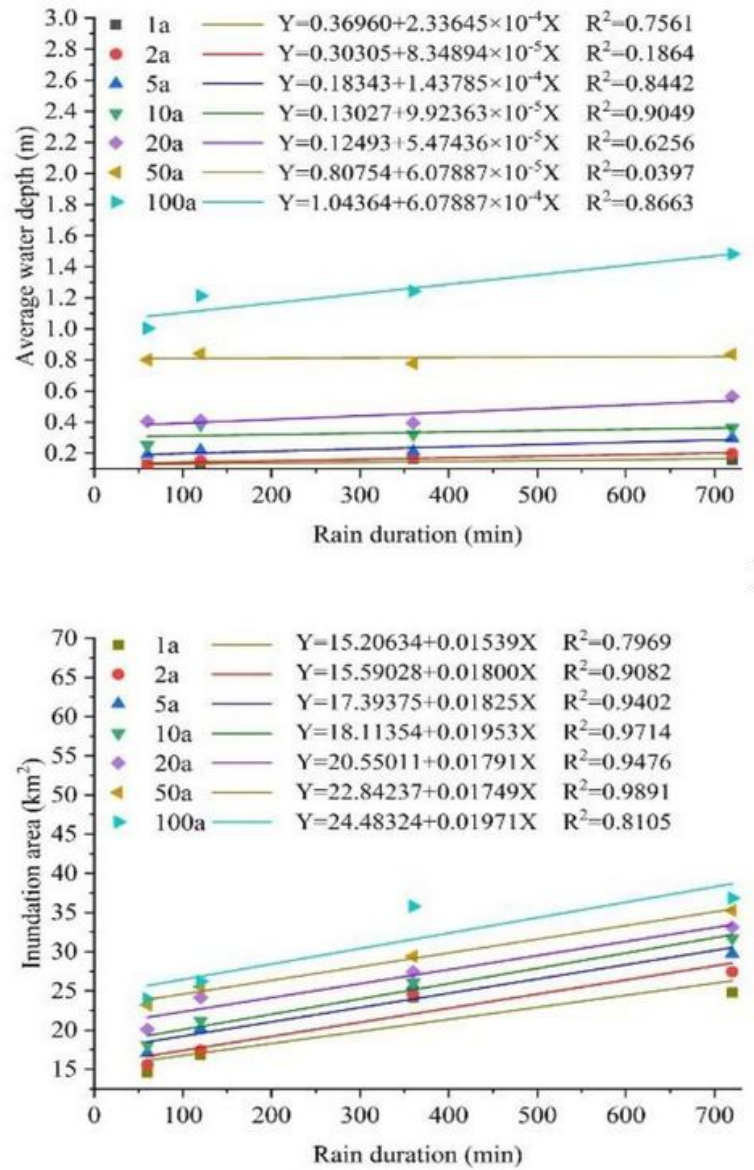

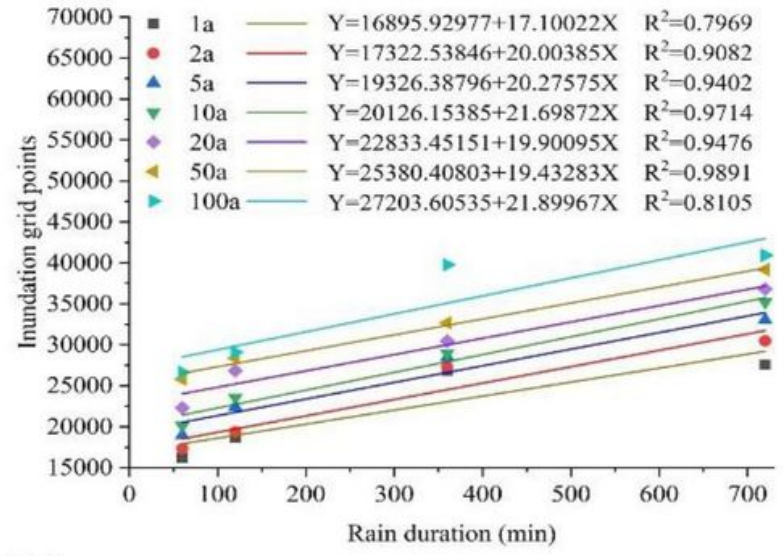

$\mathrm{R}^{2}=0.8131$

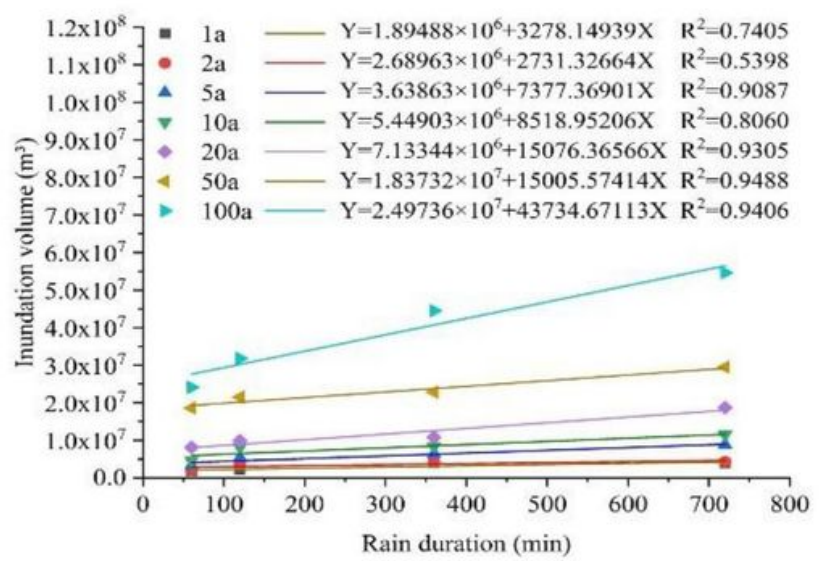

\section{Figure 15}

Trend chart of relationship between submerged water depth, submerged grid points, submerged area, submerged water volume and rain duration. (The rain duration and the four submergence indicators are linearly correlated, with an average R2 of 0.8131 .) 


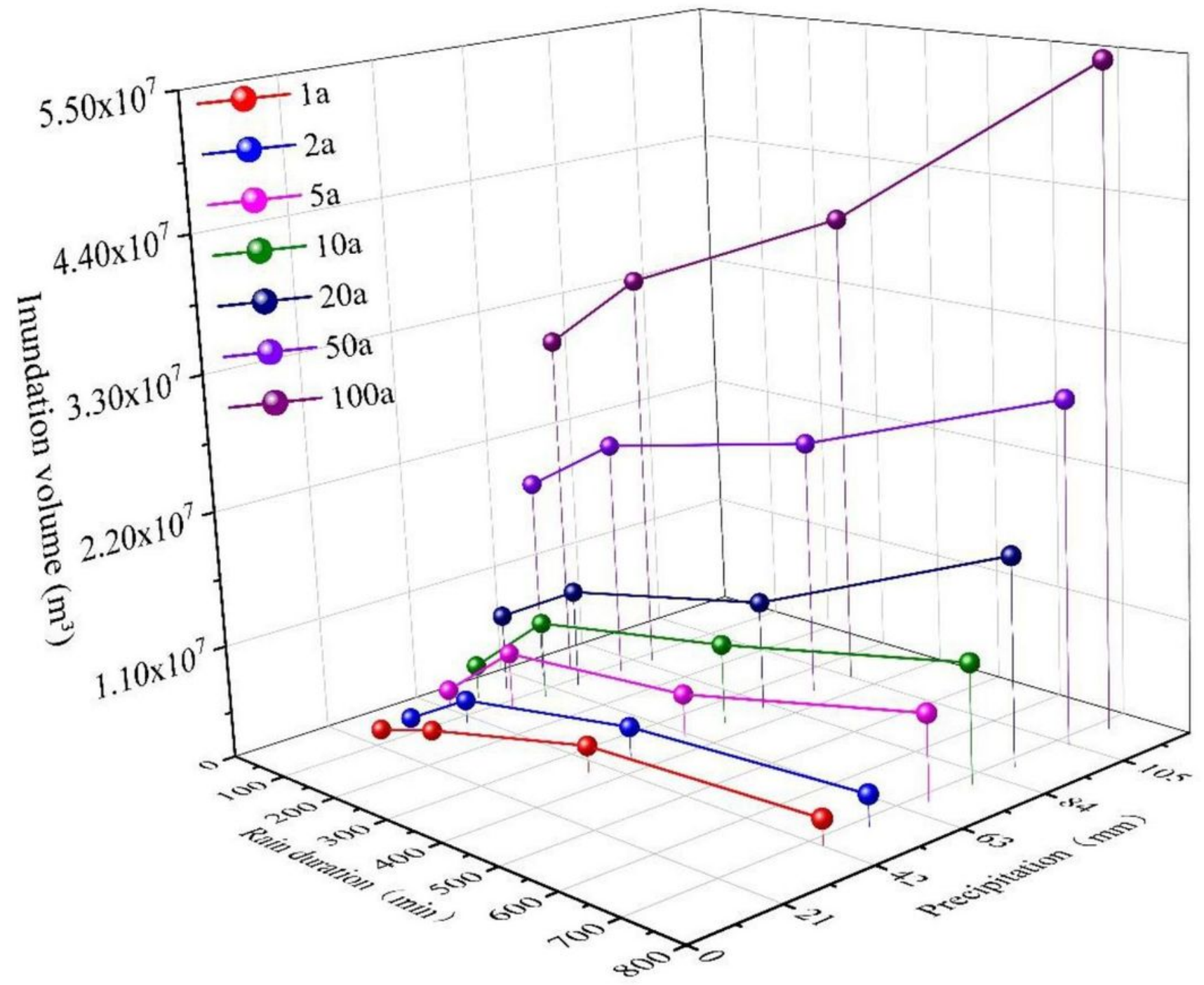

Figure 16

The relationship between submerged water volume and rainfall duration and rainfall. 


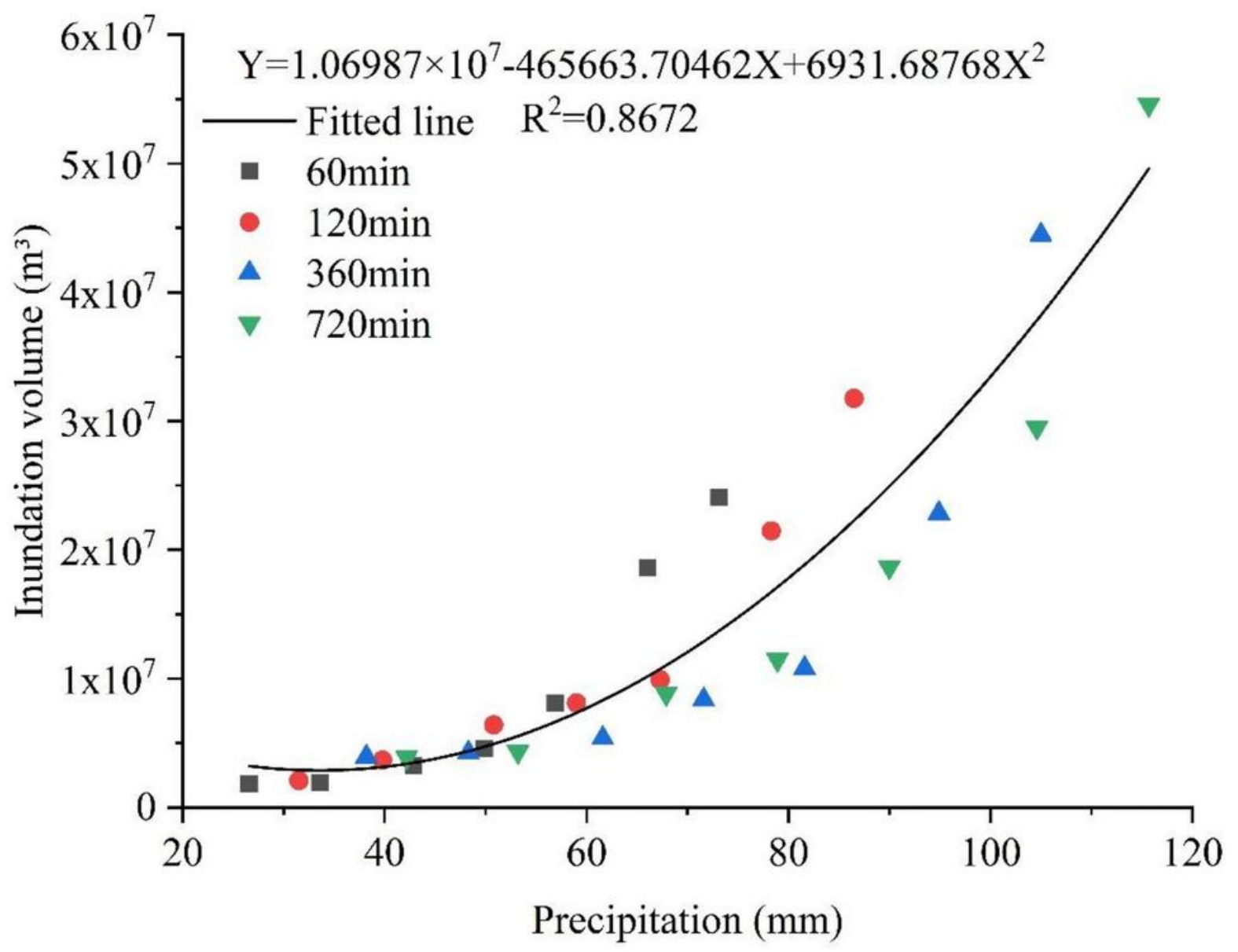

Figure 17

The relationship between submerged water volume and rainfall. 